\title{
Acoustic Study of an Air Intake System of SI Engine using 1-Dimensional Approach
}

\author{
A. A. Dahlan', M. F. Muhamad Said ${ }^{1, *}$, Z. Abdul Latiff ${ }^{1}$, M. R. Mohd Perang ${ }^{1}$, \\ S. A. Abu Bakar ${ }^{1}$ and R. I. Abdul Jalal ${ }^{2}$ \\ ${ }^{1}$ Automotive Development Centre, School of Mechanical Engineering, \\ Faculty of Engineering, Universiti Teknologi Malaysia, 81310 Johor Bahru, Johor, \\ Malaysia \\ *Email: mdfarid@utm.my \\ Phone: +075535449; Fax: +075535811 \\ ${ }^{2}$ Automotive Engineering Section, Universiti Kuala Lumpur, Malaysia France Institute, \\ 43650, Bandar Baru Bangi, Selangor, Malaysia
}

\begin{abstract}
Air intake system of an internal combustion engine plays main role in delivering fresh air from the environment to the engine and dampening the sound of the engine combustion process coming from the engine combustion process. In this study, a simulation was conducted to improve the existing air intake system design in terms of acoustic study to have better sound quality by modifying the resonators, air duct and airbox volume of the air intake module. This study implements the 1-dimensional simulation study using commercial software, correlate to the 1.6-liter natural aspirated engine. The objective of this study is to decrease the engine noise at snorkel of the air intake module without losing too much of pressure drop. At the end of this study, the analysis defines the geometry of air intake module with the recommended resonator for fabrication and physical testing. The simulation result shows that the modified air intake module meet the objective and fulfil the performance target.
\end{abstract}

Keywords: 1-Dimensional simulation; air intake system; SI engine; engine acoustic.

\section{INTRODUCTION}

Noise reduction on motor vehicle in meeting passenger comfort requirement has become a major concern among automotive industries and researchers $[1,2]$. As the internal combustion engine acts as the vehicle's power source, it also creates noise which decreases passenger comfort level and contributes to noise pollution especially in a city $[2,3]$. Tire, wind, exhaust and intake are considered as airborne noise in vehicle environment. Currently the focus is on having a quiet passenger cabin by reducing induction noise as the selling feature for any passenger vehicle $[4,5]$. Active resonator is also studied to help in various speed and load of engine to coop with different frequencies of noise [6]. In designing a vehicle, a prediction of noise is very important to reduce the noise locally on the system. This can be done through the usage of simulation tools to achieve the optimum design in a lesser amount of time and lower cost [7, 8]. Among the commercial tools that are available in current market are AVL Boost, GT-POWER, Ricardo Wave and Lamps which are using 1-D theory for acoustical analysis $[9,10]$.

Air intake module (AIM) is a breathing system for the engine to provide clean air from the environment to the combustion chamber. The system must have a minimum flow 
resistance and reduces radiated noise at the snorkel $[11,12]$. The system includes air duct, snorkel and airbox cleaner. The air enters through snorkel and went straight to air filter box before entering the engine's intake manifold. Air filter box provides a filter that stops dust from entering the combustion chamber to prevent performance drop and protect components from unnecessary wear. The clean air then enters the air duct going straight into the intake manifold. It then leaves the intake manifold when the intake valve opens to enter the combustion chamber. As the intake valve closes, the accumulation of clean air at the intake manifold causes high pressure to build up and travel backwards to the snorkel causing noises. A good AIM design reduces snorkel noise by attenuating the noise travelling backwards $[7,13]$. Tuning of acoustic needs several iterations. By using a 1D simulation tool, it reduces product development time and cost $[10,14]$.

This study uses GT-POWER as the simulation tool for 1D modelling. The 1D model is built and simulation results for transmission loss and pressure drop has been correlated with the engine. The 1D air intake module simulation model is then connected to the validated engine module and exhaust module. The sound pressure levels are simulated using the software. At the end of this process, a design has been recommended. The scope of this study is to improve air intake module system design using resonators for a passenger vehicle. The objectives are to construct a baseline $1600 \mathrm{cc}$ engine model, correlate the constructed model with the actual engine performance test, and conduct acoustic study to the air intake module performance in order to propose a new air intake module design having a better acoustic performance.

\section{ENGINE MODEL DEVELOPMENT}

The engine model has been built starts from the intake airbox system until exhaust system. This was to ensure that the constructed model represents the real engine condition. To model the air intake module, 3D CAD geometries of these components were used. The 3D geometries were discretized to convert into one-dimensional environment model. Inlet and outlet diameters of each pipe as well as their length were defined in the model. Upper and lower airbox were defined by their volume. Discharge coefficient was also introduced to represent pressure losses of the air filter.

A similar discretization process was applied to the intake and exhaust manifold. Here, the intake and exhaust runners were modelled using bend pipe object. Basically, these objects consider the pressure loss because of bending geometry. The diameters of inlet and outlet, as well as the angle and bending radius were defined to model these runners. Intake plenum was defined using Y-split part, where the volume of each runner section was applied.

The most important step in engine modelling is to use the right combustion model. In this study, the purpose was to investigate the effect of intake system on engine performance as well as engine 'breathing'. Therefore, a non-predictive combustion model known as SI Wiebe function was more suitable. This combustion model simply imposes a burn rate as a function of crank angle. Here, the burn rate was calculated from measured in-cylinder combustion pressure at various engine speed with full load conditions.

To model intake and exhaust valves, it was required to define the characteristics of a cam-driven valve including its geometry, lift profiles and flow characteristics. Both intake and exhaust valves open timing were set according to the real engine configuration. Figure 1 shows the complete constructed model of the engine. The model was simulated at engine speed of 1000 to $6500 \mathrm{rpm}$ with $500 \mathrm{rpm}$ interval at WOT condition. The simulation is run without exhaust system and mufflers. This is to ensure that the engine 
breathing has been modelled correctly. At this stage, exhaust system is represented by orifice diameter that can achieve targeted back pressure. After the simulation completed, the results of engine performance were plotted. These results were then used to correlate the model with experimental data.

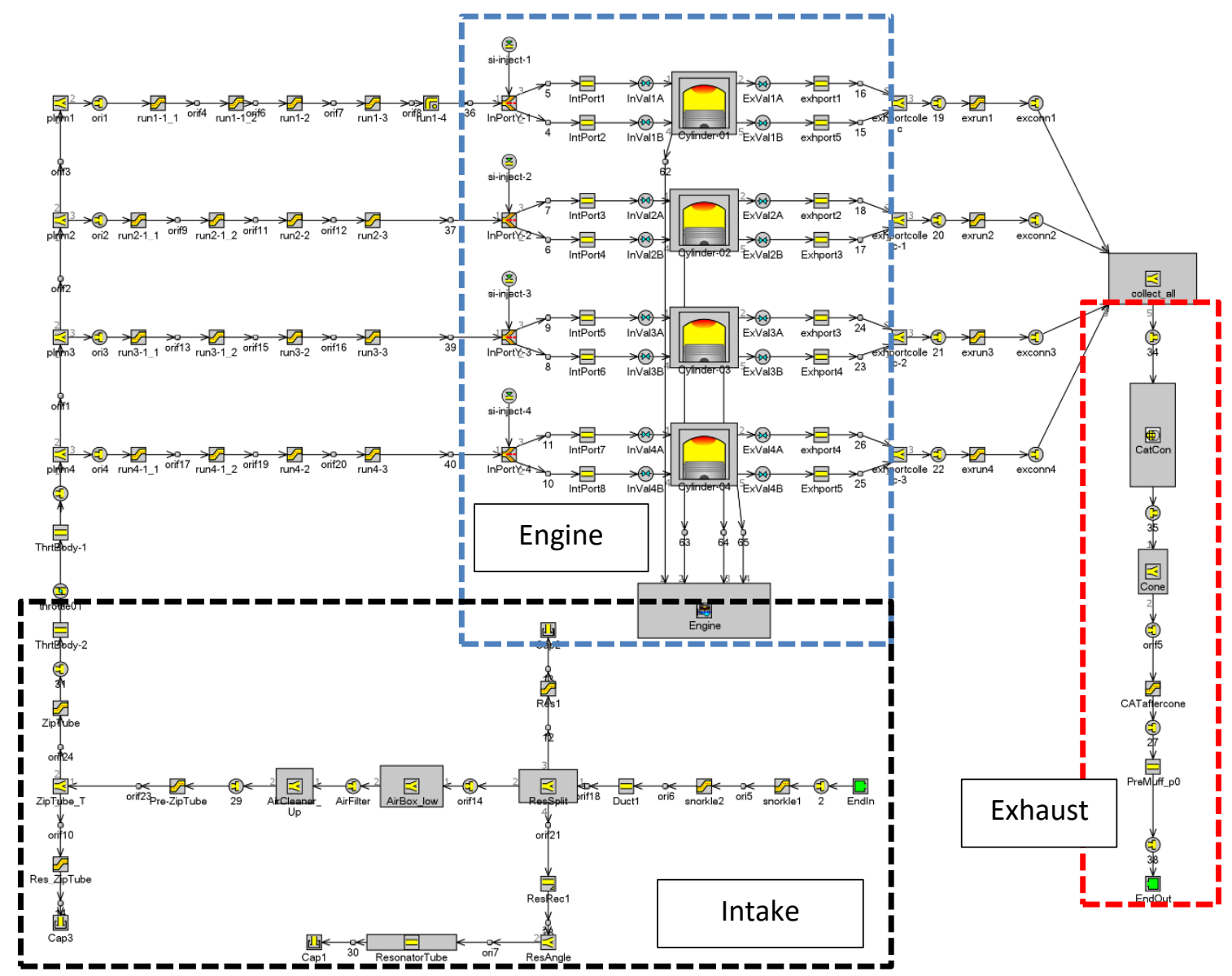

Figure 1. Complete constructed model of 1.6L natural aspirated engine.

\section{ENGINE PERFORMANCE MODEL CORRELATION}

To verify the accuracy of the constructed model, the model has been correlated to the measured data. The accuracy of the constructed model has been verified by comparing the simulated results to the actual measured data. In the engine modeling, the best practice is to make sure that the differences between measured and simulated data are less than $2 \%$ for the intake system and 5\% for the exhaust system and for engine performance comparison.

As depicted in Figure 2, the constructed engine model for 1.6 L engine was well correlated. All the comparisons were within recommended values. Thus, this correlated model can be used for further studies, especially on the acoustic of intake system as well as engine performance prediction. 

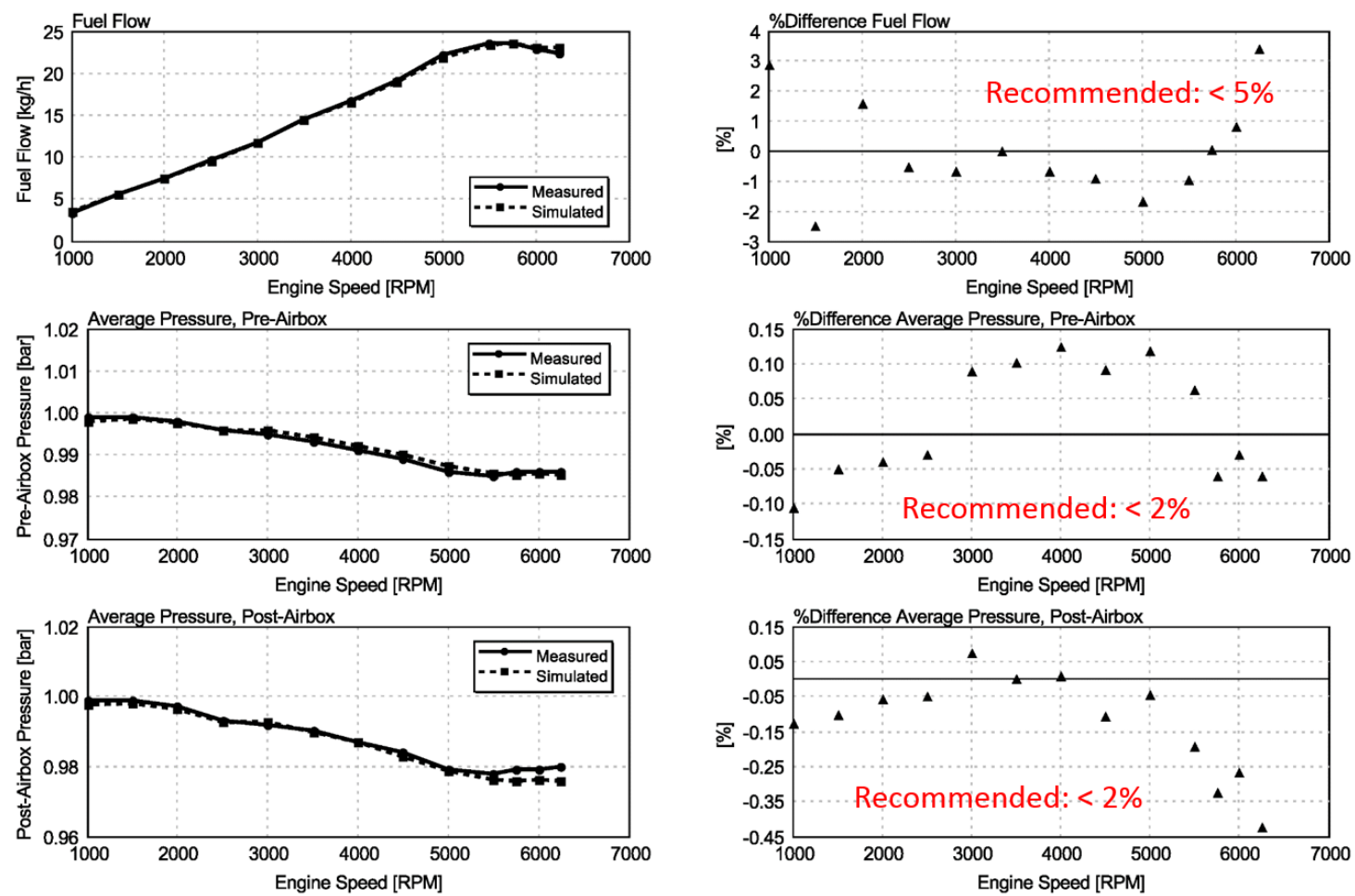

(a) fuel flow, pre-airbox and post-airbox.
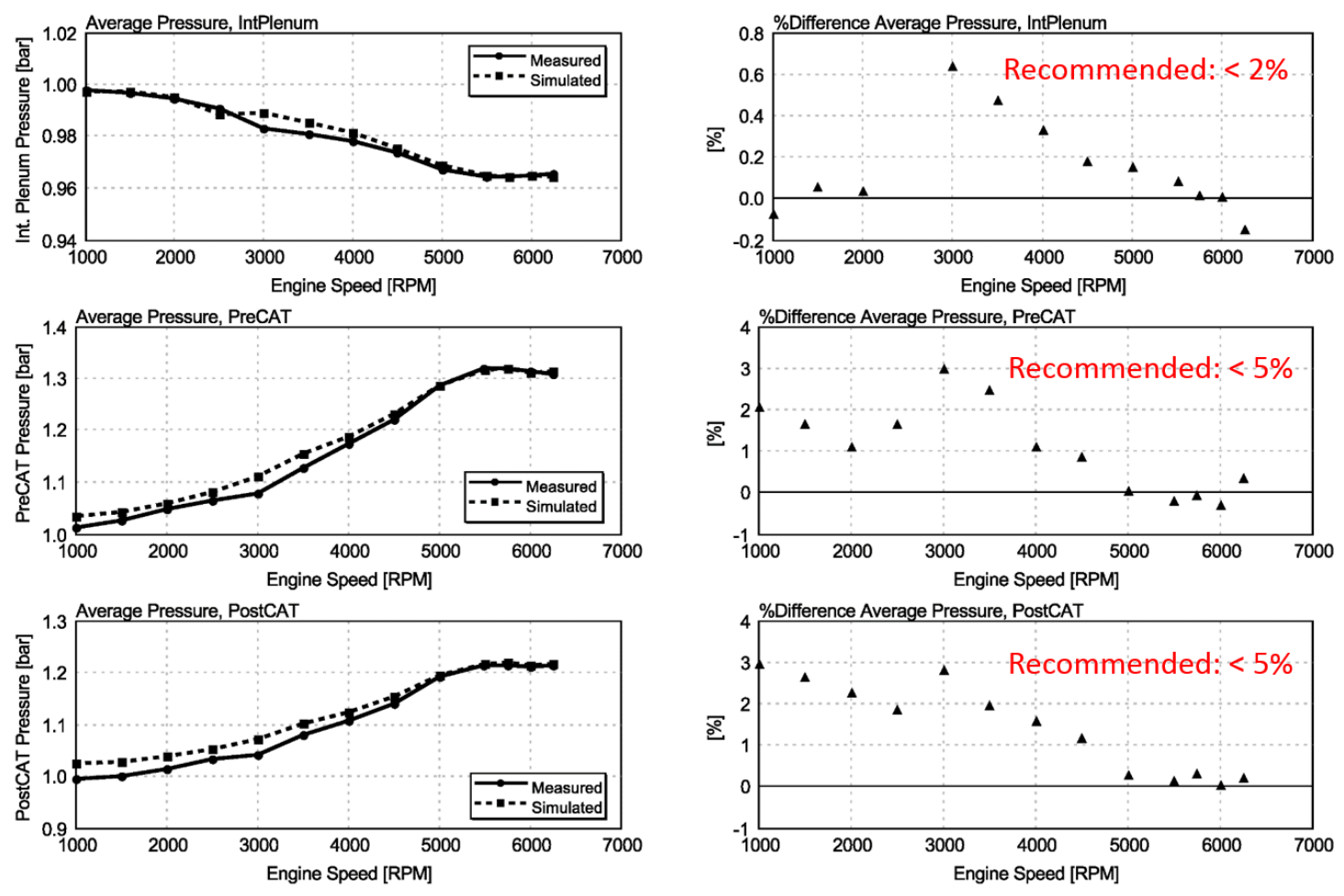

(b) intake plenum, pre-CAT and post-CAT. 

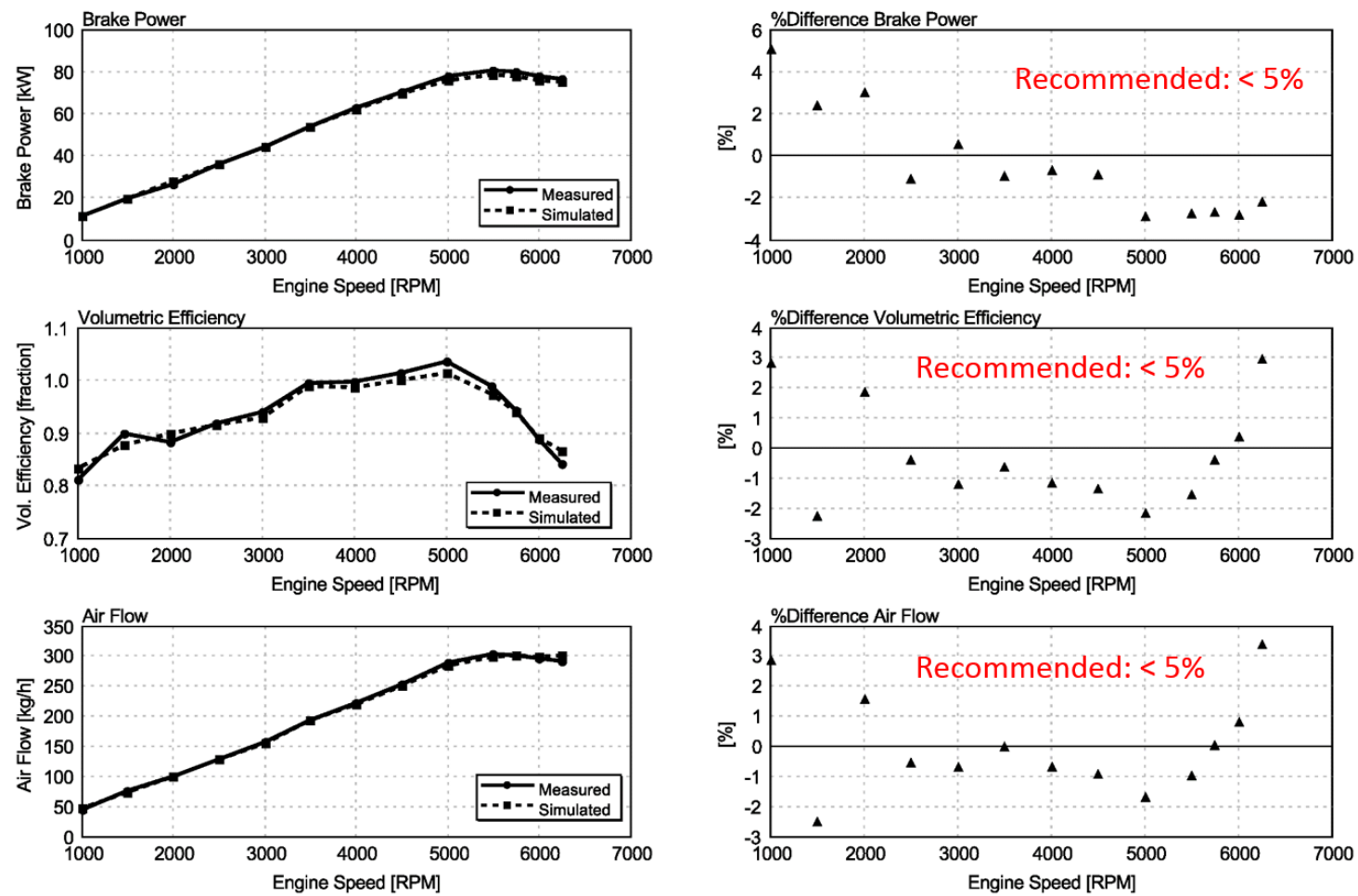

(c) brake power, volumetric efficiency and air flow.
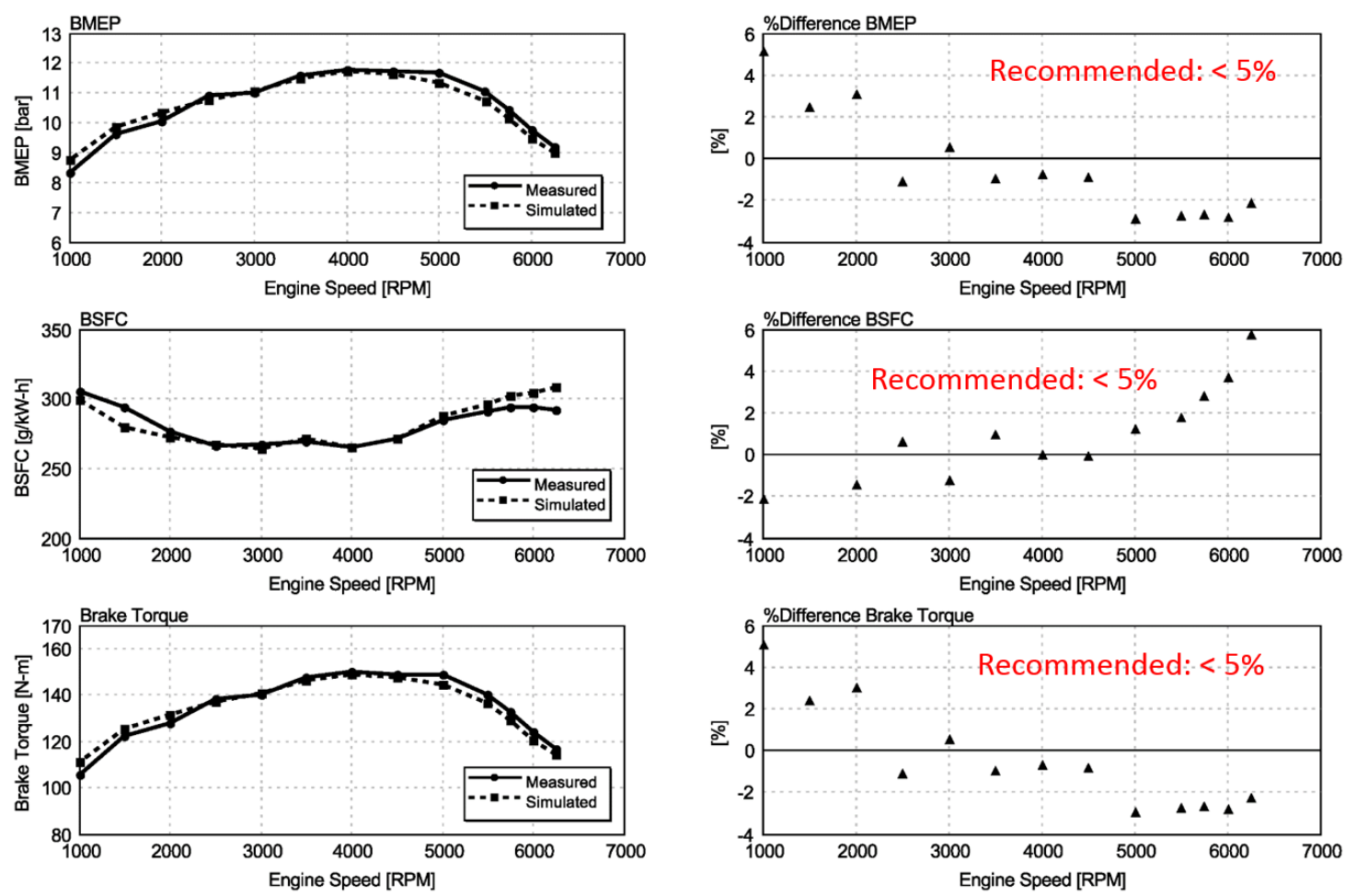

(d) BMEP, BSFC and brake torque.

Figure 2. Comparison of engine performance from simulated and measured data. 


\section{MODEL CORRELATION}

\section{Sound Pressure Level Model Correlation}

The prediction of SPL at Snorkel for baseline purpose was carried out at WOT. The simulated results of SPL for Baseline model were compared to measured data. This was to ensure that the constructed model is well correlated to actual data. Figure 3 shows the comparison of simulated SPL with the measured data at various orders.

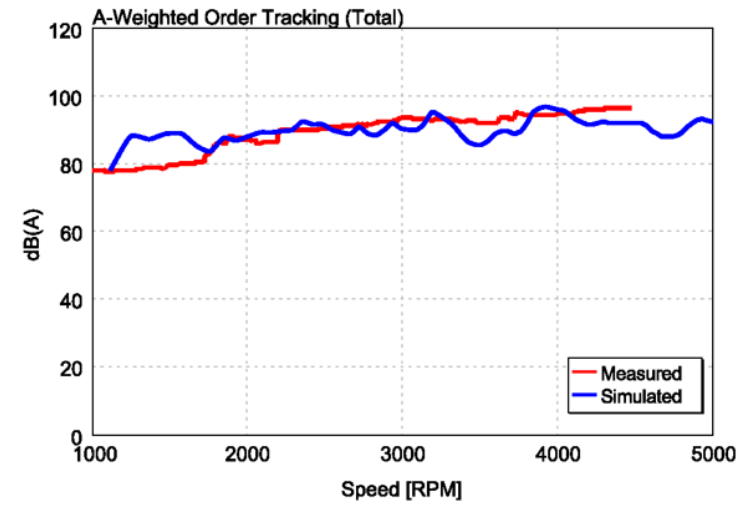

(a)

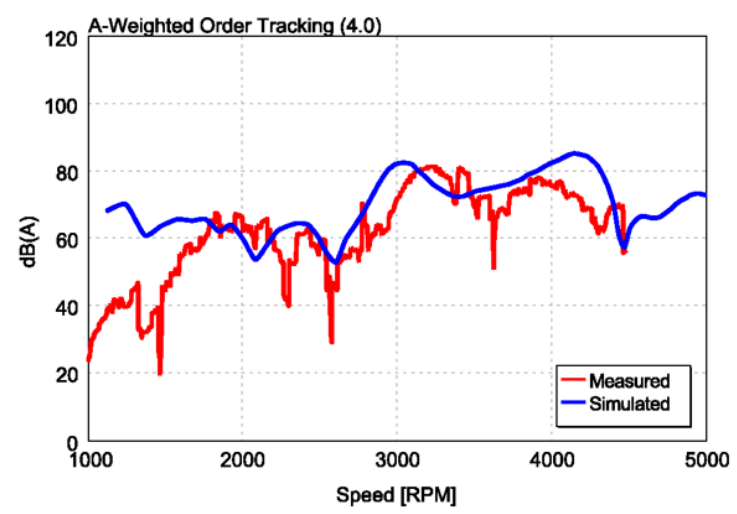

(c)

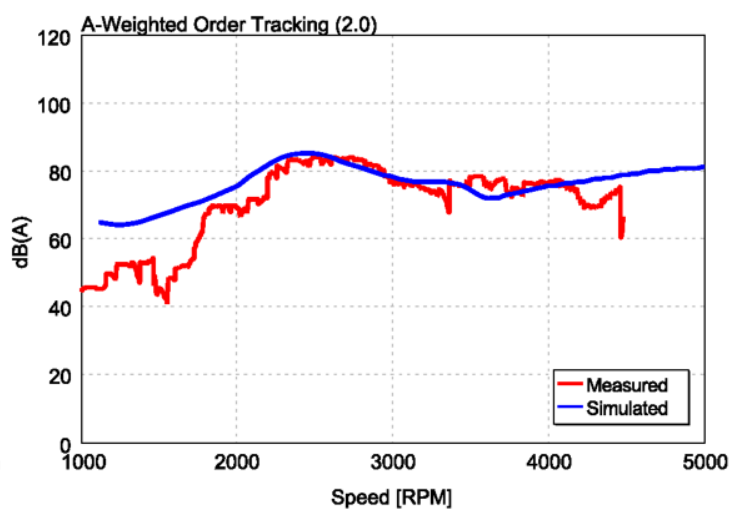

(b)

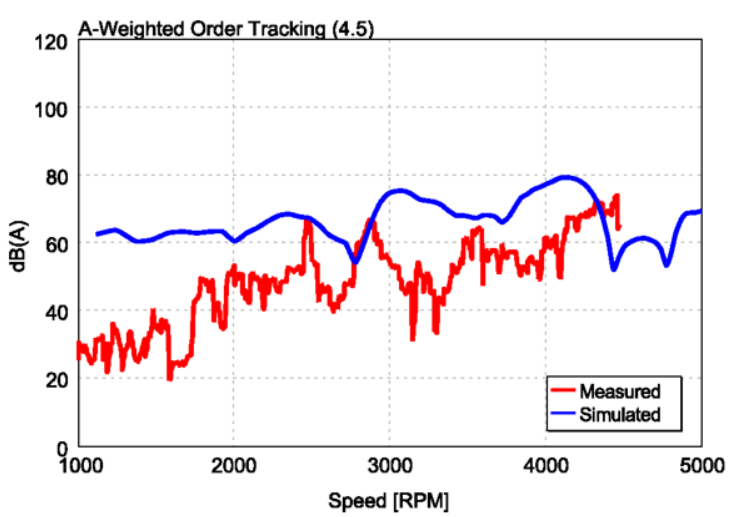

(d)

Figure 3. Comparison of (a) total weighted and (b) second; (c) fourth and; (d) $4.5^{\text {th }}$ order tracking from simulated SPL and measured data.

\section{Effect of Resonators on Transfer Function}

The 1D analysis was performed to understand the effect of intake resonators on the sound quality at snorkel. In this simulation, the effect of each resonator on the Transfer Function and the sound pressure level were performed. Figure 4 shows the air intake module of a baseline model which include four resonators. The baseline of air intake module was simulated at component level to determine the Transfer Function which include all fours resonators. The model was then modified by removing each resonator to study their effect on resonance frequencies. As represented in Figure 5, each resonator contributes to the enhancement at specific frequencies. 


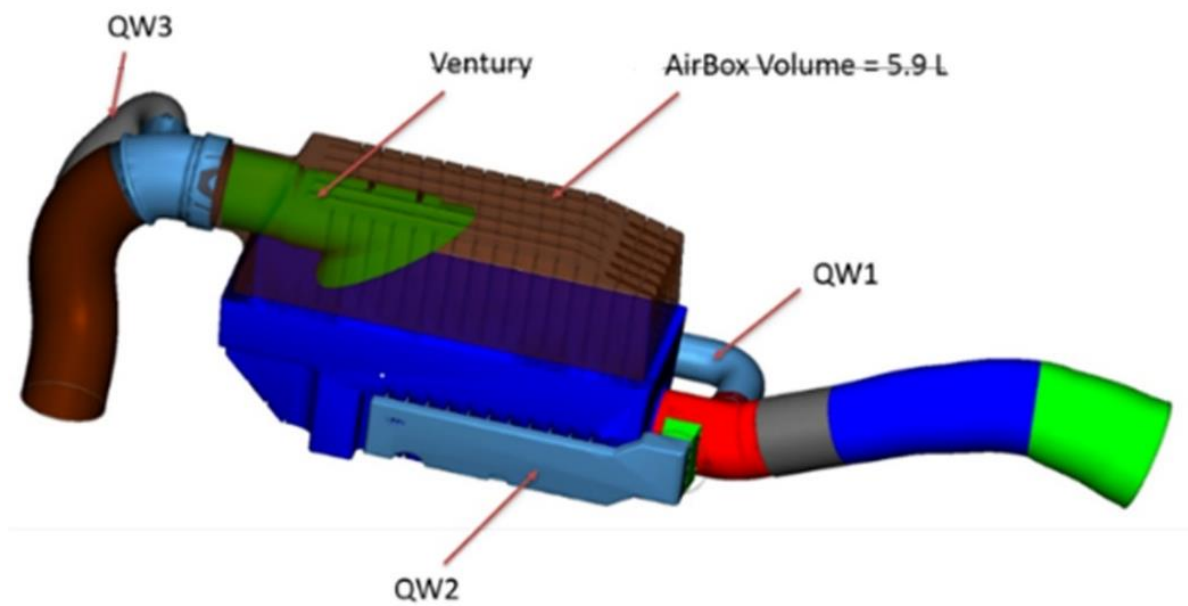

Figure 4. Air intake module of a baseline 1.6L engine.

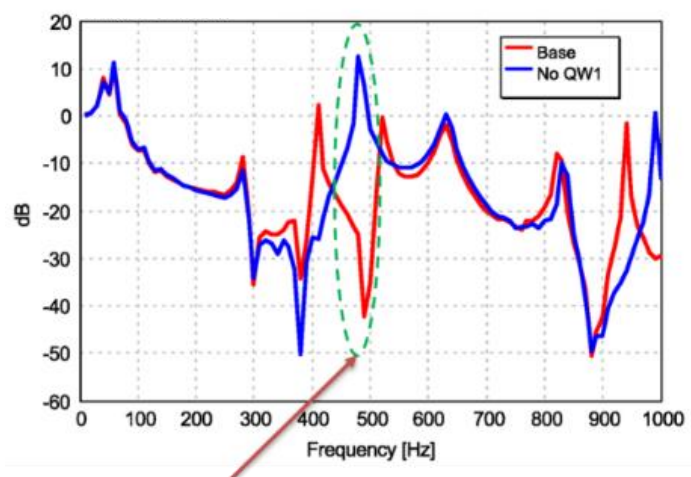

QW1 improves strongly at around $500 \mathrm{~Hz}$.

(a)

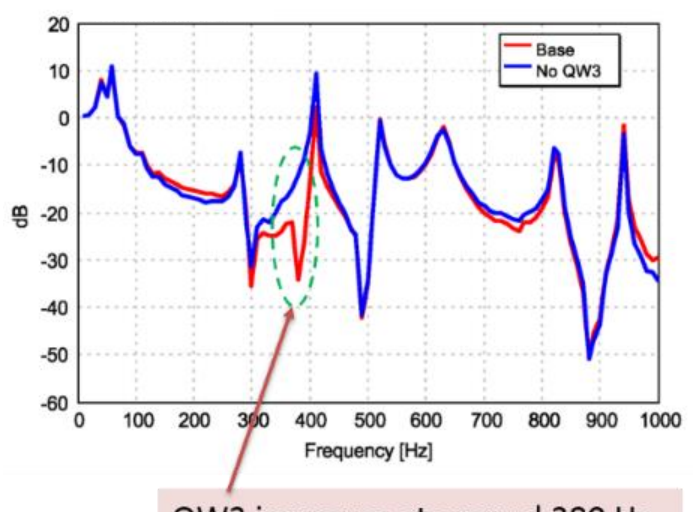

QW3 improves at around $380 \mathrm{~Hz}$.

(c)

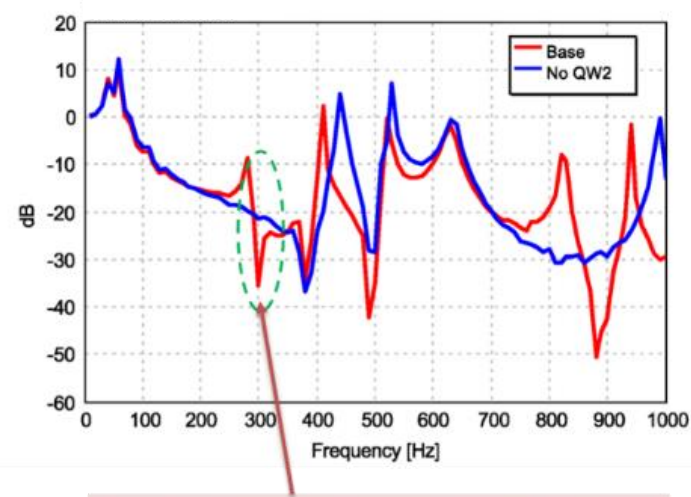

QW2 improves at around $300 \mathrm{~Hz}$, but produce side effect at $280 \mathrm{~Hz}$.

(b)

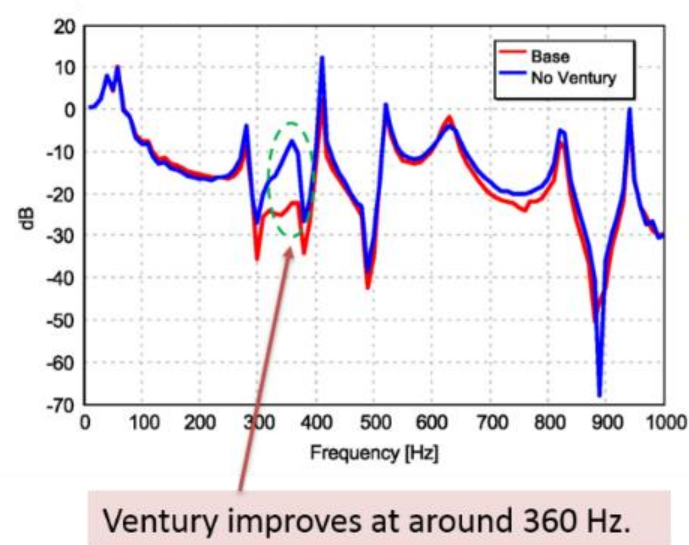

(d)

Figure 5. Effect of removing (a) QW1 resonator; (b) QW2 resonator; (c) QW3 resonator and; (d) ventury on transfer function.

It is found that QW1 improve the transfer function at around $500 \mathrm{~Hz}$, while QW2 improves transfer function at $300 \mathrm{~Hz}$ with some side effects at $280 \mathrm{~Hz}$. On one hand, 
QW3 improves the performance at around $380 \mathrm{~Hz}$, and on the other hand, QW4 improves the performance around $360 \mathrm{~Hz}$.

Another simulation was carried out to determine the effect of replacing QW1 with Helmholtz. Figure 6 shows that by replacing QW1 with Helmholtz resonator with the specification mentioned, it has improved the transfer function at wider range of frequencies. Based on this finding, the modified versions of AIM were proposed. Figure 7 and Figure 8 illustrate the Propose 1 that implements Helmholtz instead of QW1.

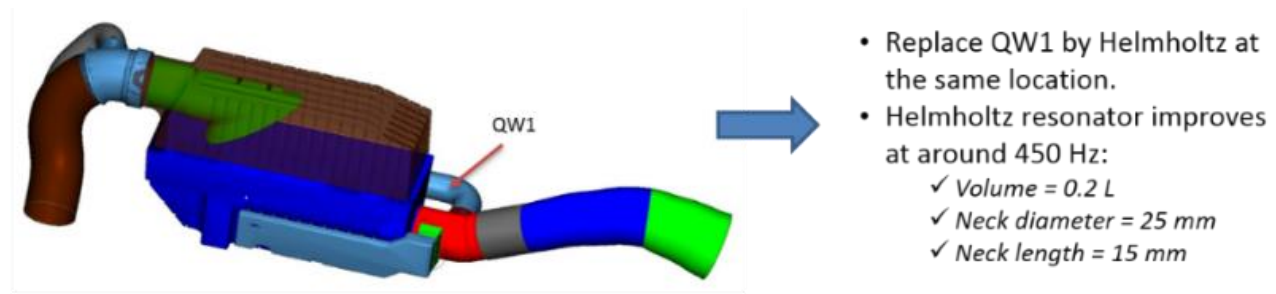

By replacing QW1 with Helmholtz resonator, it improves the transfer function at wider range of frequency.

Helm1 improves at around $450 \mathrm{~Hz}$.

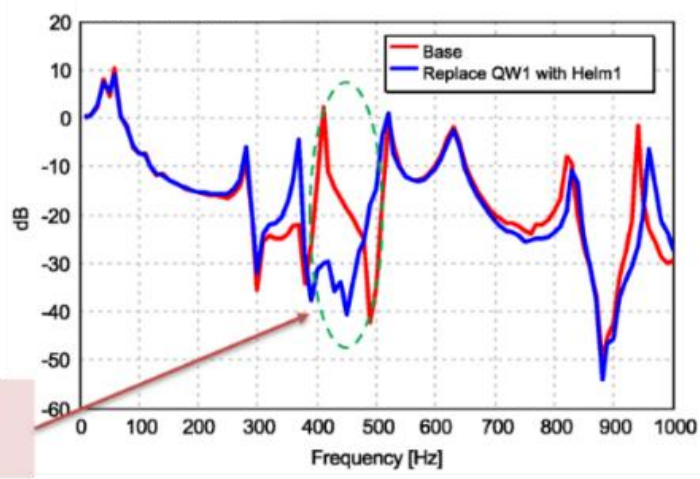

Figure 6. Replace QW1 with Helmholtz.

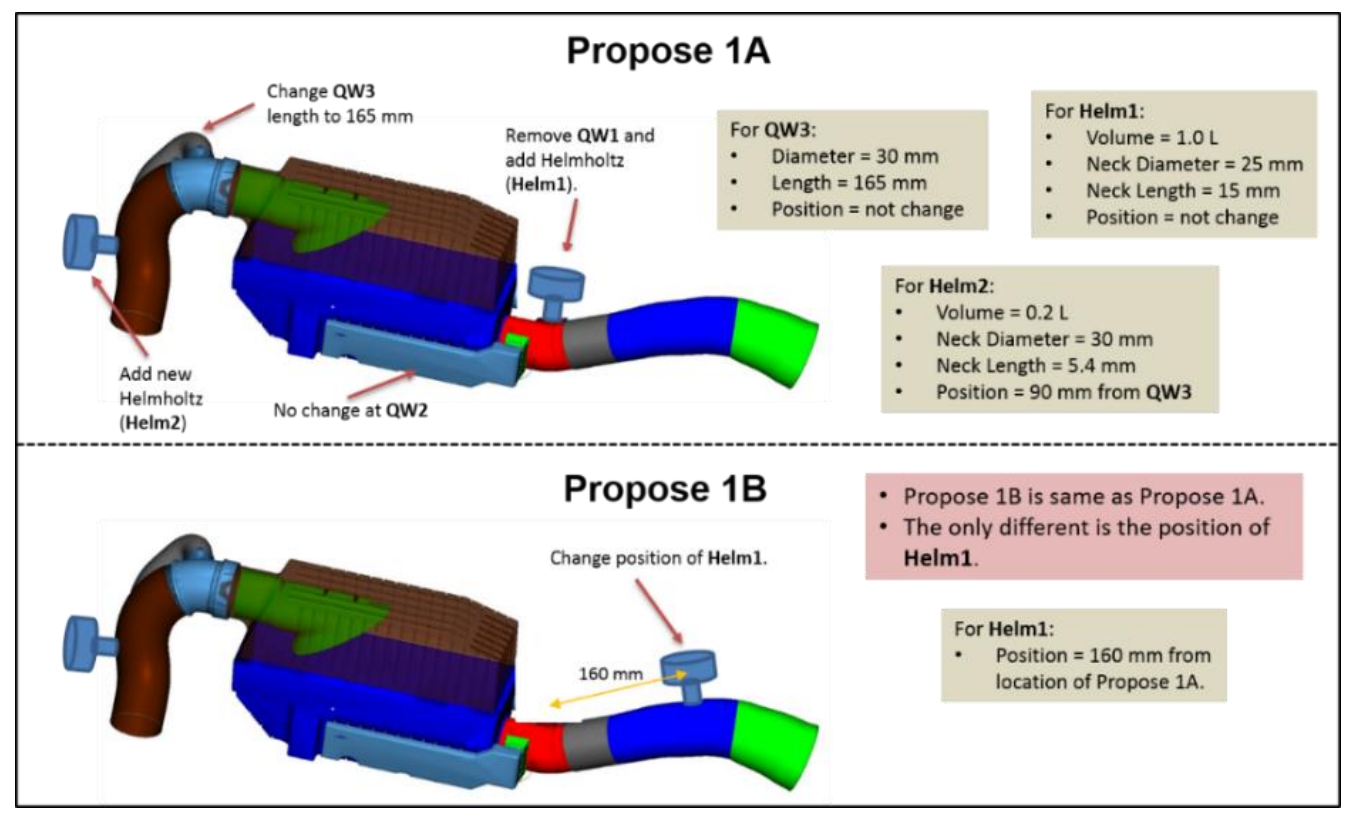

Figure 7. Propose 1 with Helmholtz (standard airbox volume). 


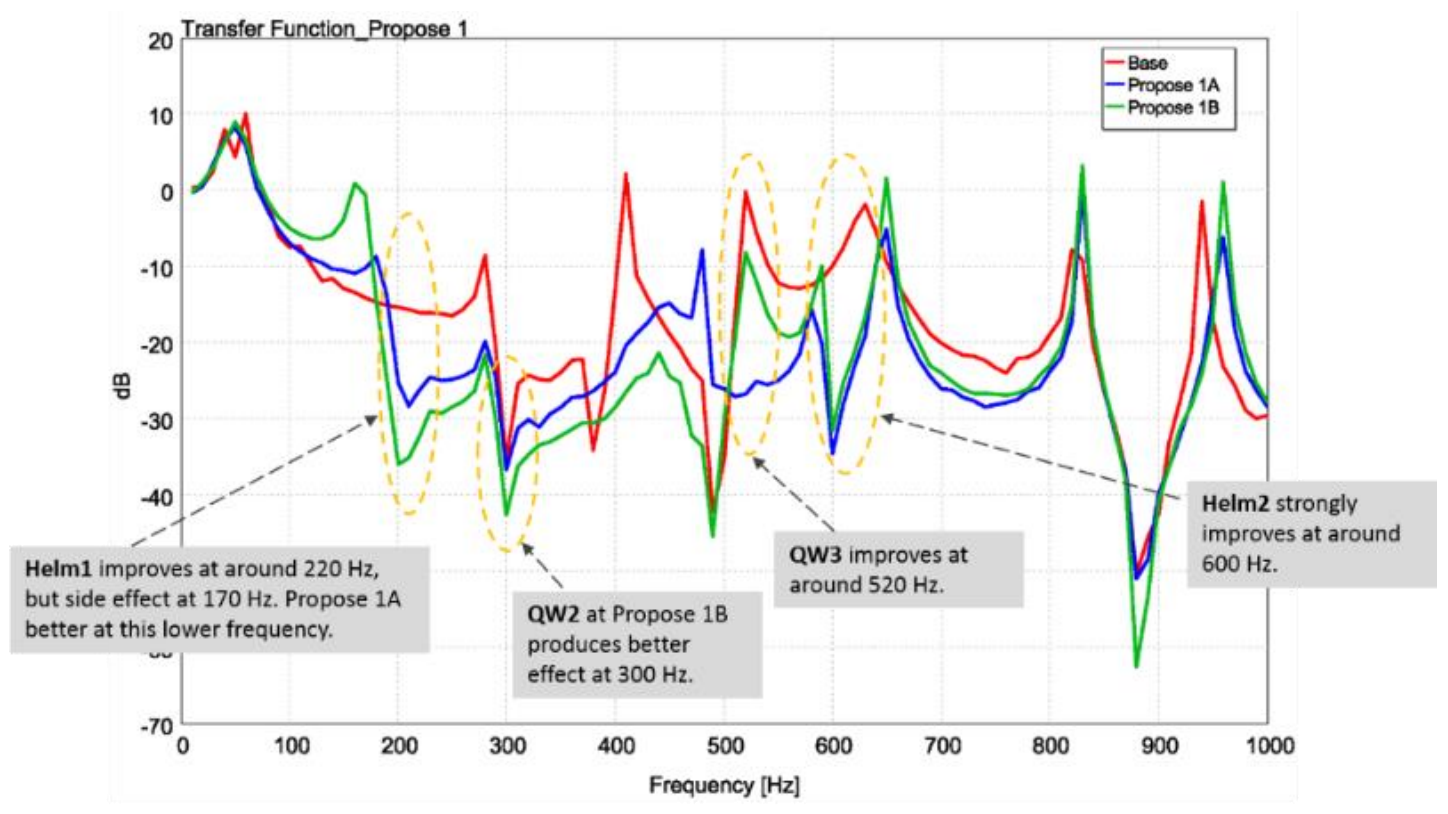

Figure 8. Simulation of transfer function for Propose 1.

Propose 2 was introduced to understand the effect of QW2. Figure 9 and Figure 10 show the location of resonators and the simulated Transfer Function of Propose 2. Transfer Function between Propose 1 and Propose 2 were compared and depicted in Figure 11. Further simulations were carried out to understand the contribution of Airbox volume on the Propose 1 and Propose 2 as shown in Figure 12.

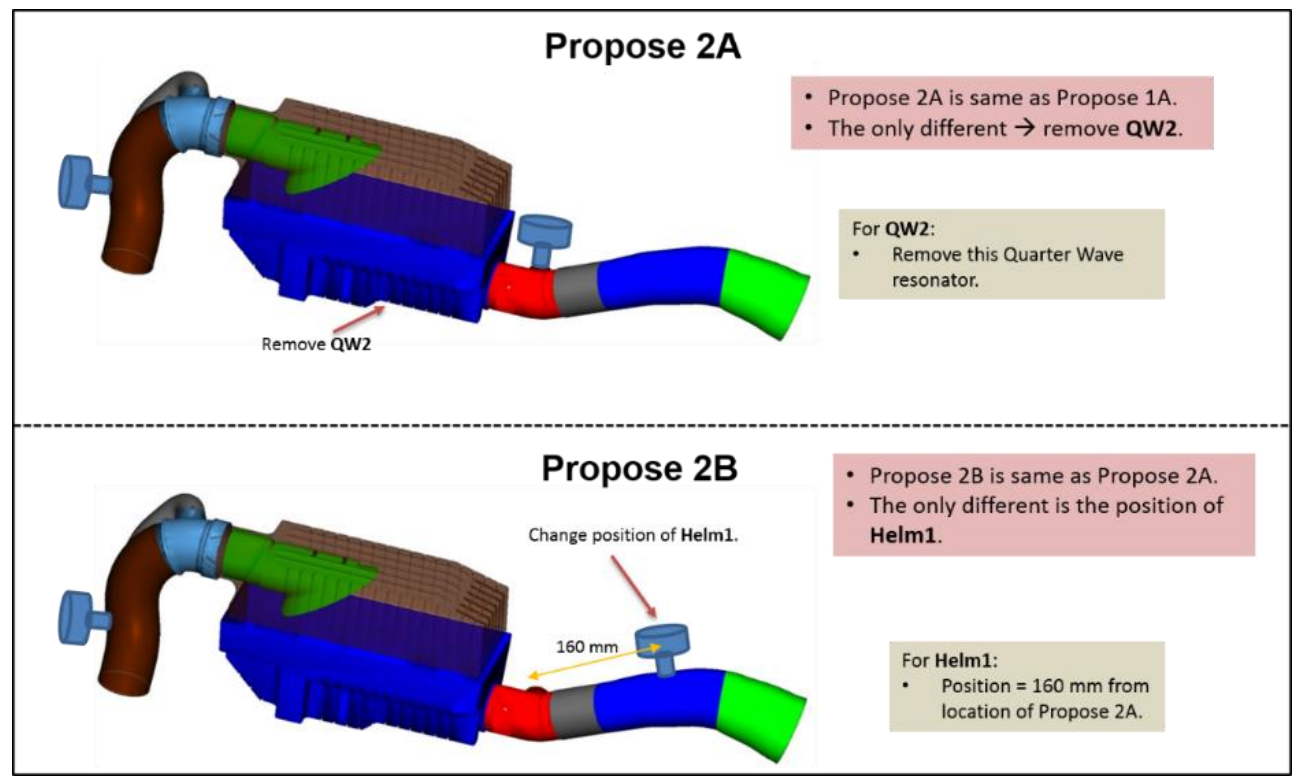

Figure 9. Propose 2 by removing QW2 (standard airbox volume). 


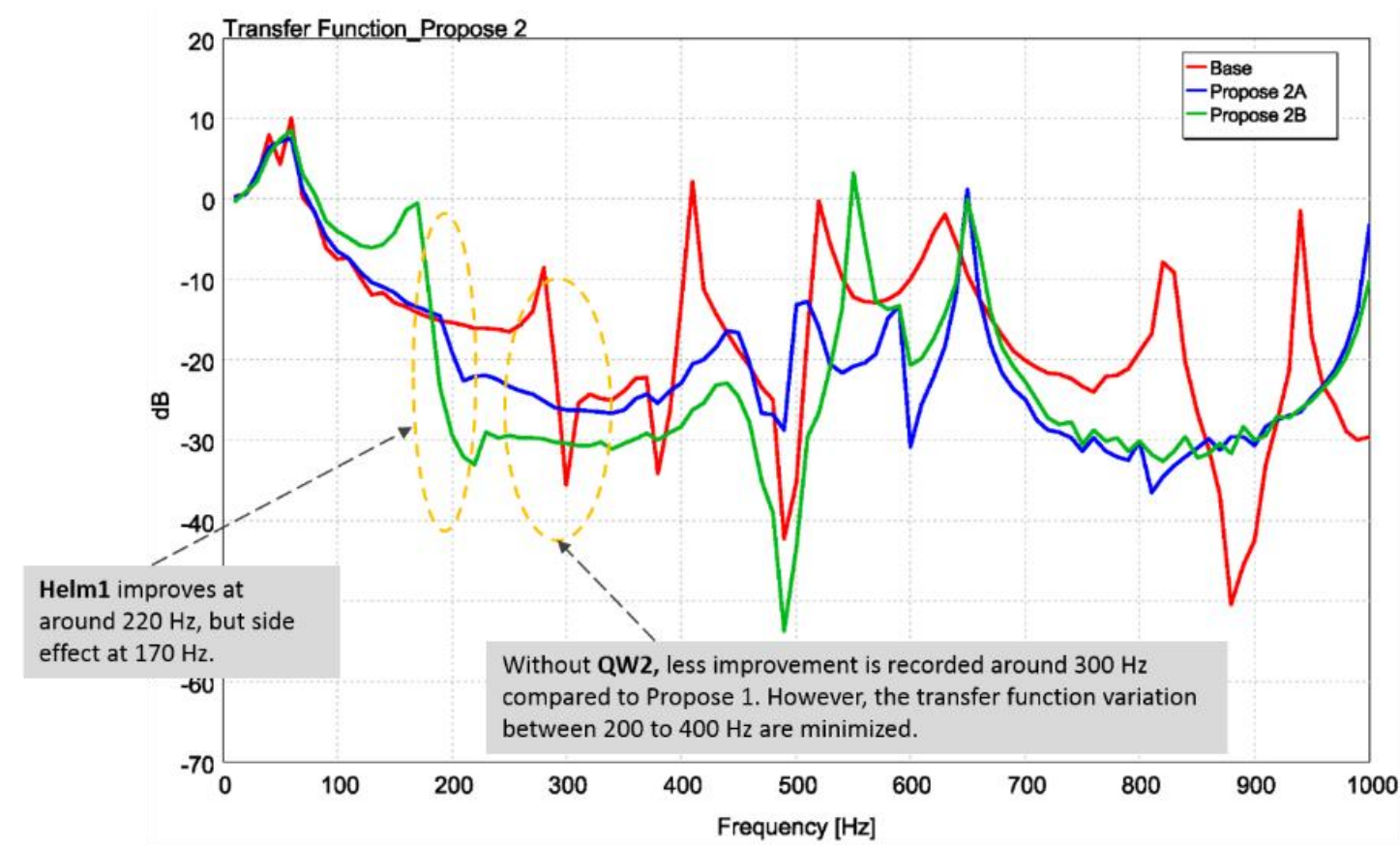

Figure 10. Simulation of transfer function for Propose 2.

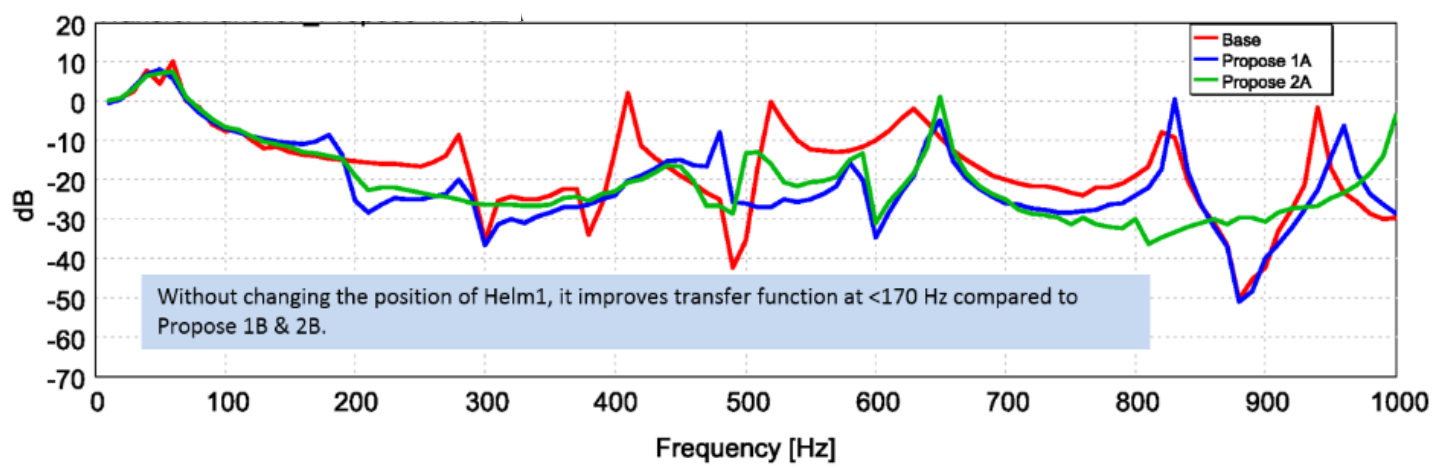

(a)

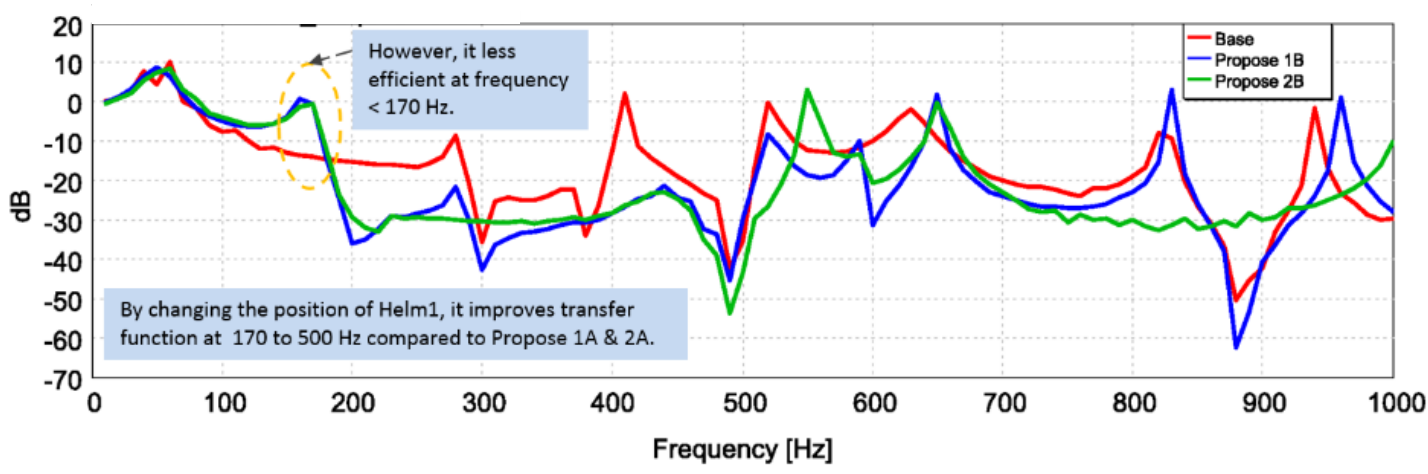

(b)

Figure 11. Comparison of transfer function between Propose 1 and Propose 2. 


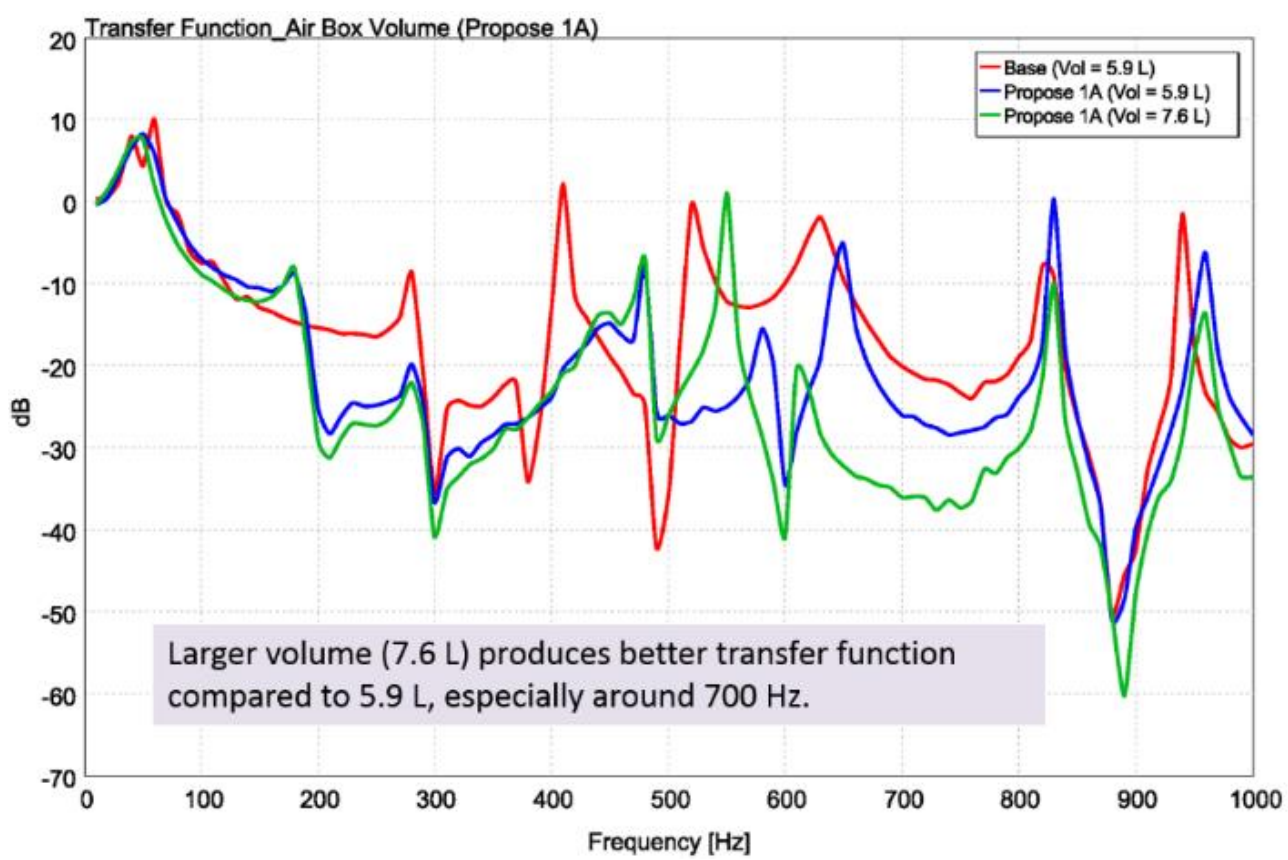

(a)

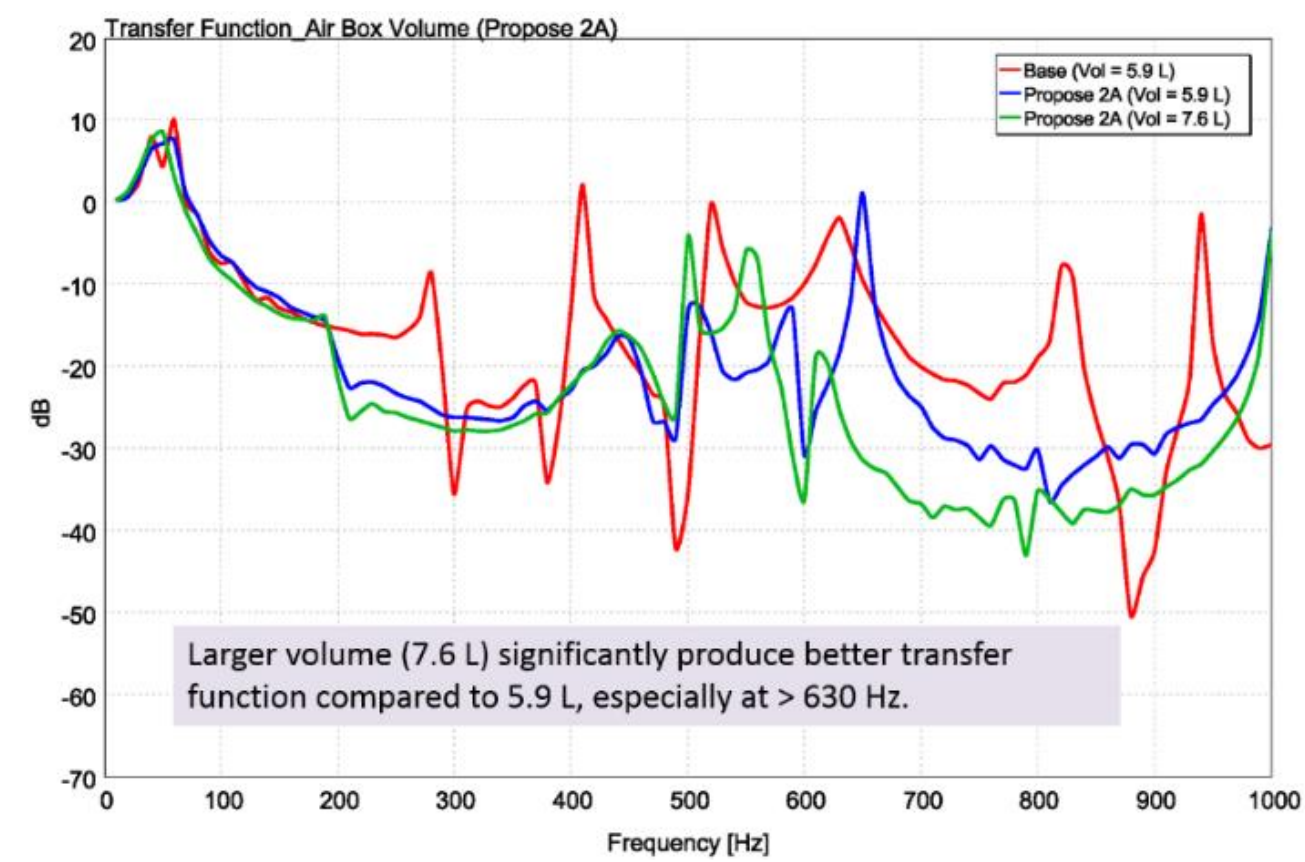

(b)

Figure 12. Transfer function at different airbox volume of (a) Propose 1 (b) Propose 2.

\section{SPL FOR PROPOSE 1 AND PROPOSE 2}

Further analysis was performed to simulate the acoustic performance generated by Propose 1 and 2. The simulation was performed by simulating the model from 1000 to $6000 \mathrm{rpm}$ at WOT. The SPL was recorded by placing a microphone at $10 \mathrm{~cm}$ before the snorkel. Here, the analysis was carried out for Propose 1A and Propose 2A due to the better Transfer Function as in Figure 11. In this simulation, the effect of Airbox volume was also investigated. The simulated SPL are illustrated in Figure 13. Further analysis of 
SPL for larger airbox volume was also performed. The configuration of resonators is shown in Figure 14. Comparison of SPL between Propose 1A and 2A at similar airbox volume are shown in Figure 15.

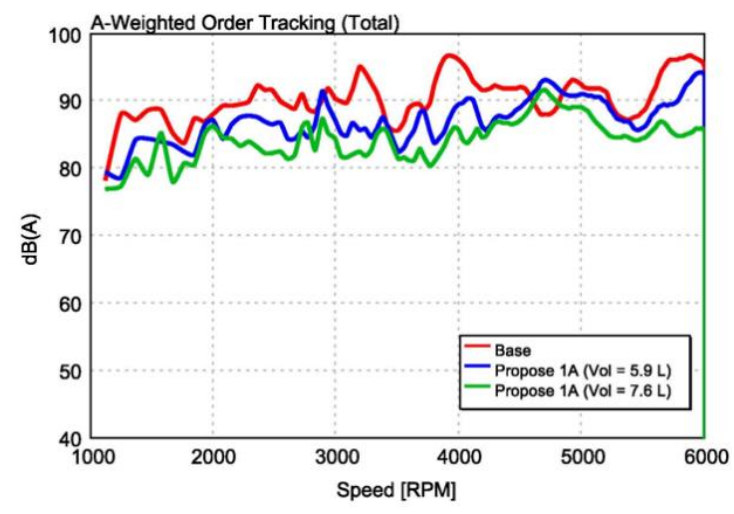

(a) total

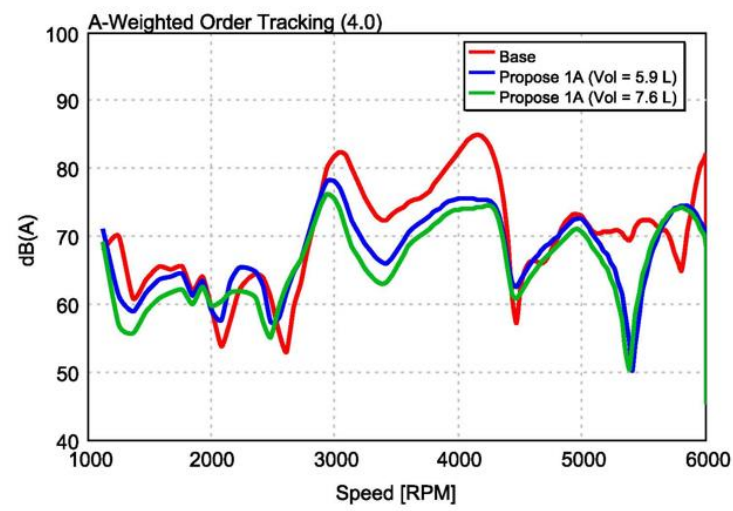

(c) $4^{\text {th }}$ order

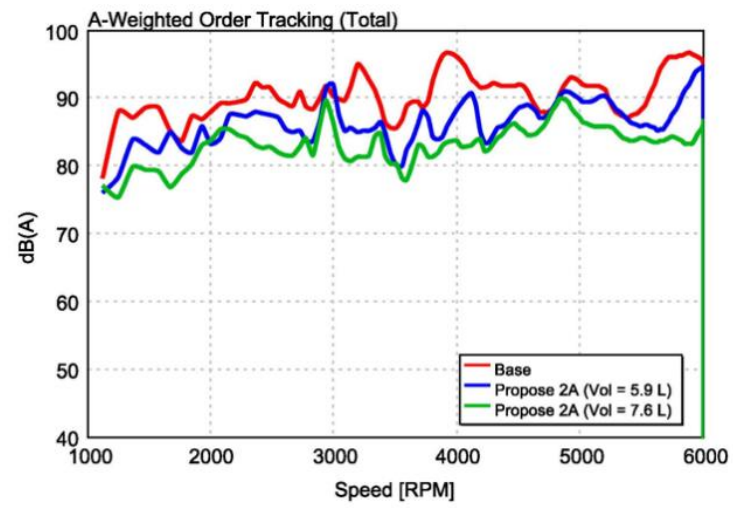

(e) total

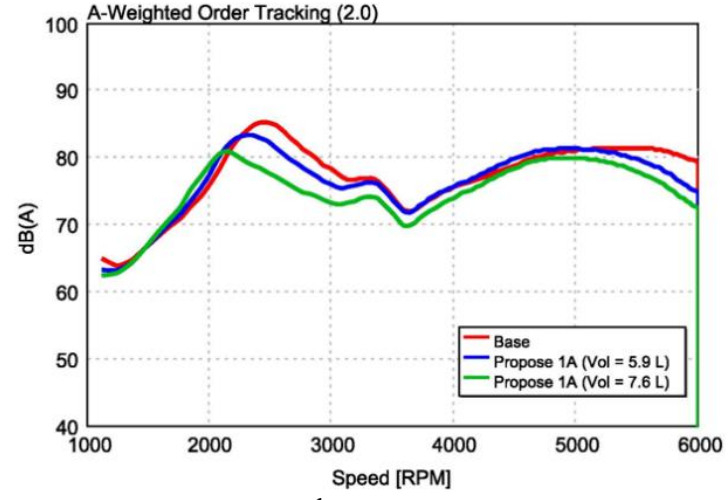

(b) $2^{\text {nd }}$ order

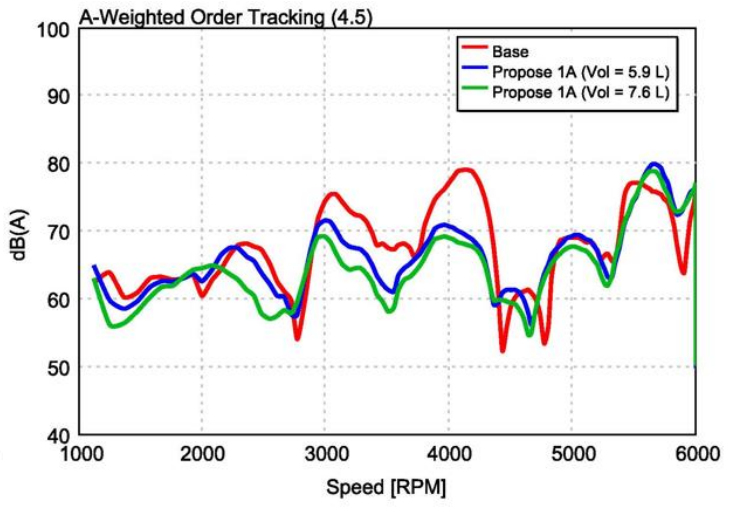

(d) $4.5^{\text {th }}$ order

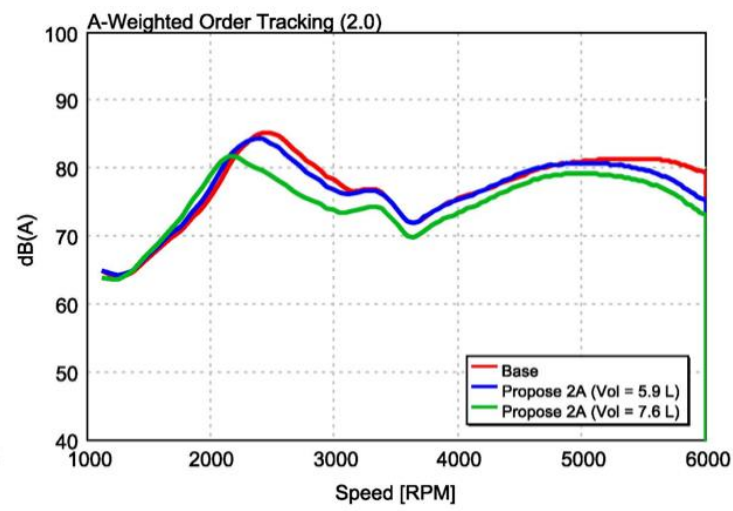

(f) $2^{\text {nd }}$ order 


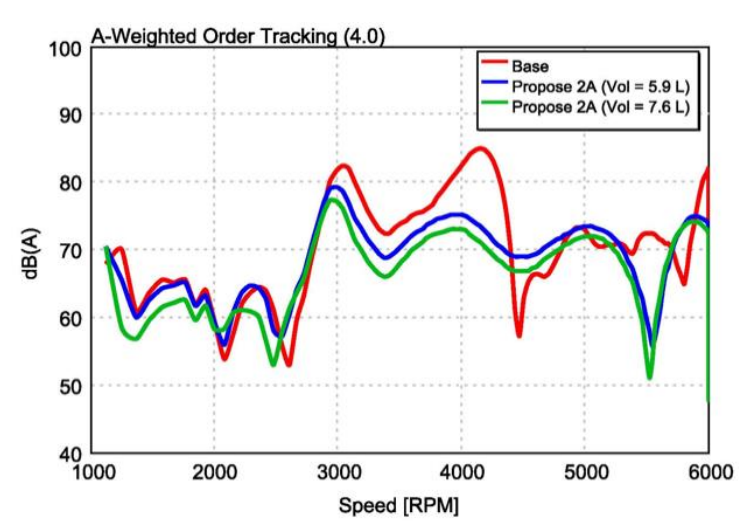

(g) $4^{\text {th }}$ order

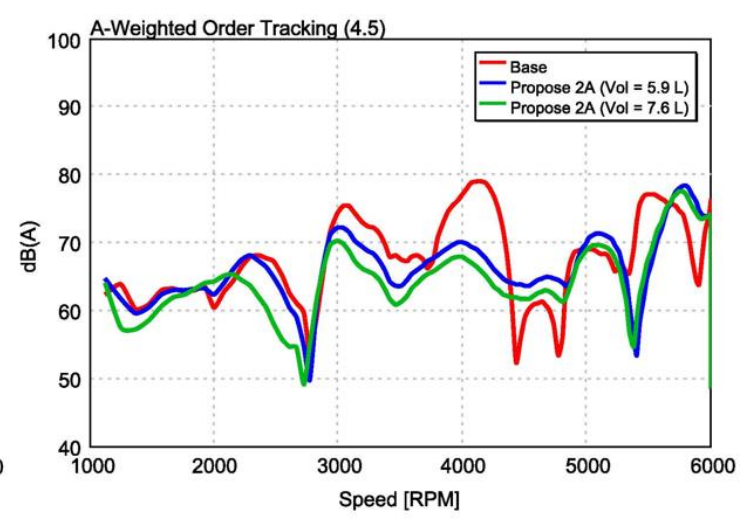

(h) $4.5^{\text {th }}$ order

Figure 13. Simulated SPL at different airbox volume of Propose 1A (a)-(d) and; Propose 2A (e)-(h).

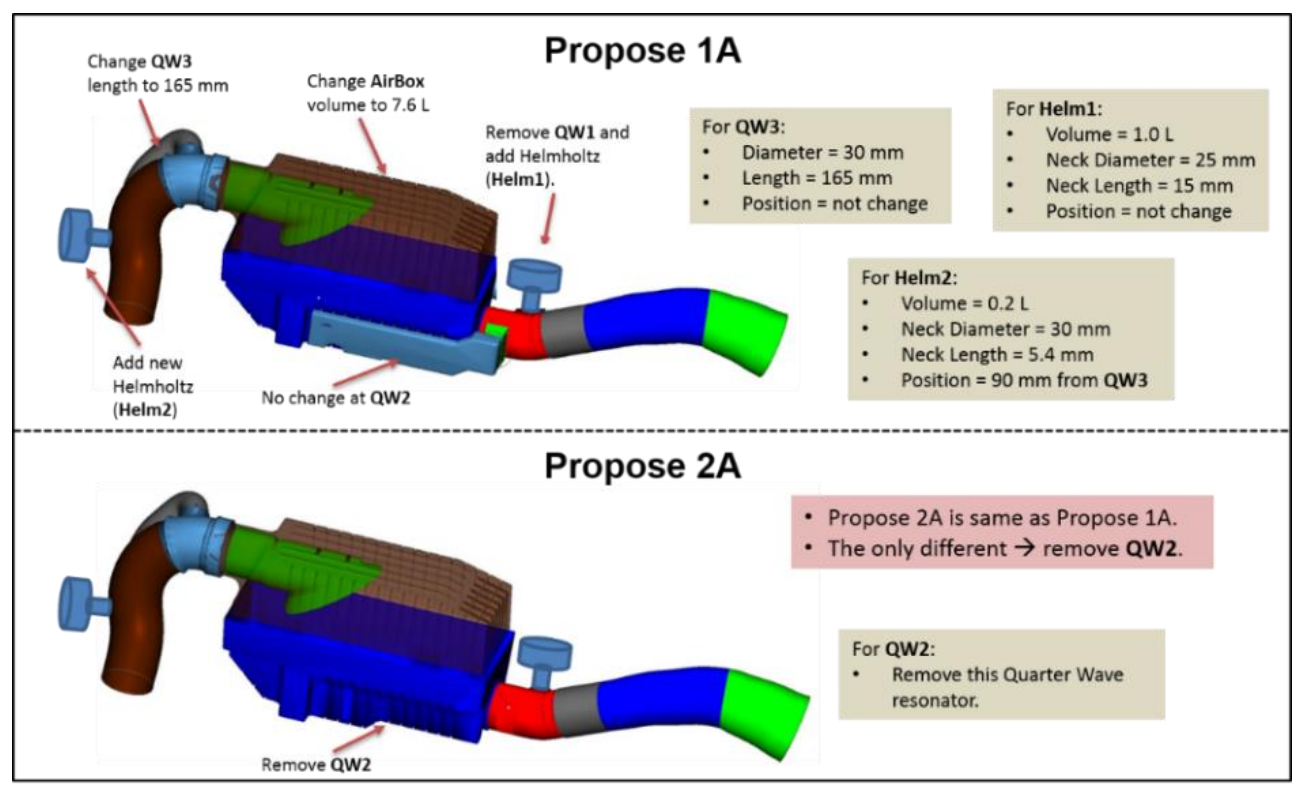

Figure 14. Configuration of resonators for a larger airbox volume.

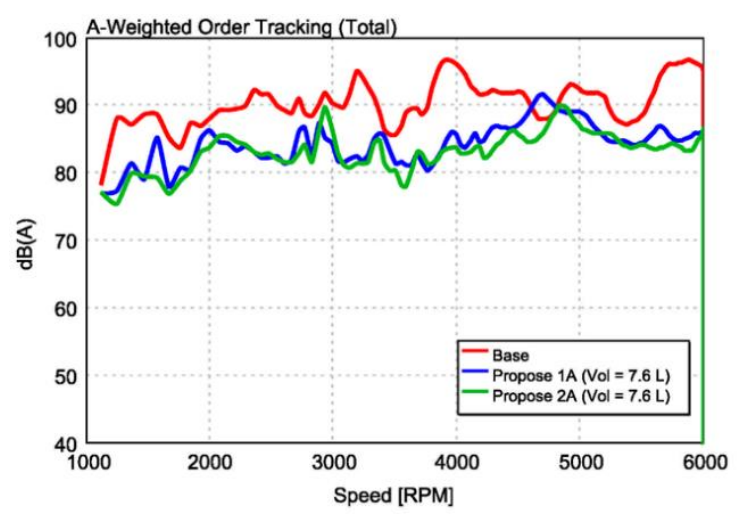

(a) total

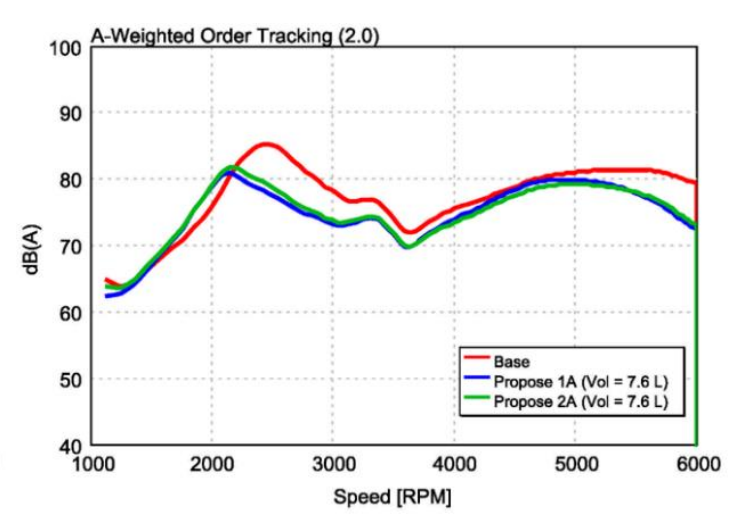

(b) $2^{\text {nd }}$ order 


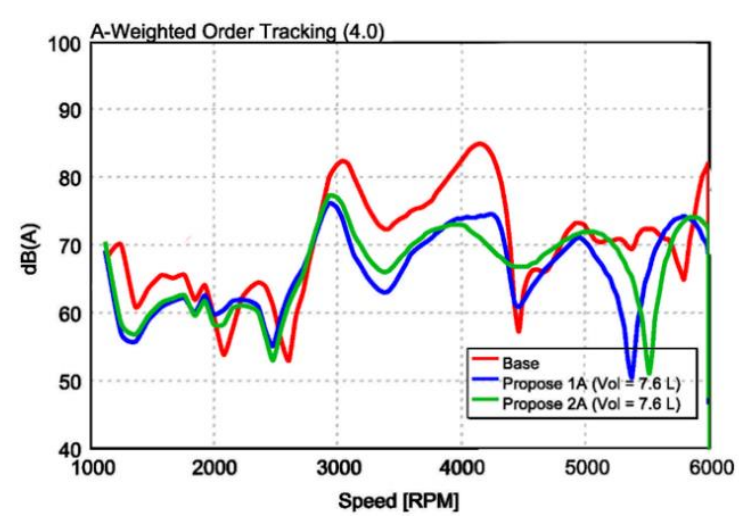

(c) $4^{\text {th }}$ order

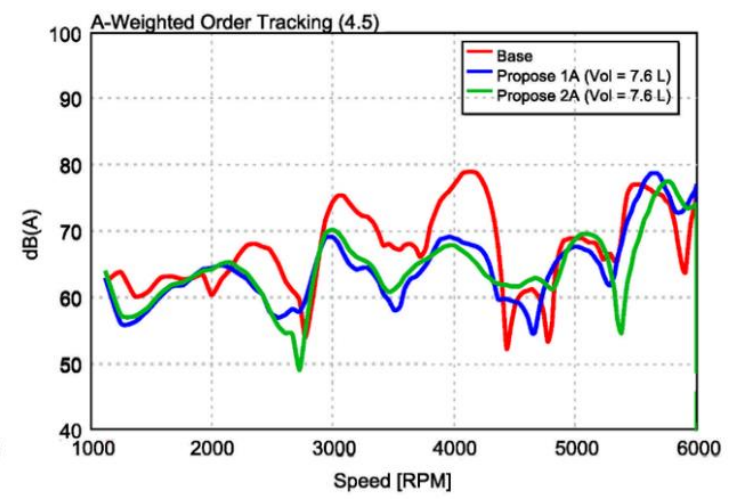

(d) $4.5^{\text {th }}$ order

Figure 15. Comparison between Propose 1A and 2A at similar airbox volume.

\section{IMPROVEMENT OF PROPOSE 2A}

The design of Propose 2A has been improved. In this section, the effect of intake duct length and its diameter were studied. The simulated SPL concludes that the duct length of $400 \mathrm{~mm}$ was suggested based on results on Figure 16. In terms of duct diameter, 50 mm size was recommended based on results on Figure 17.

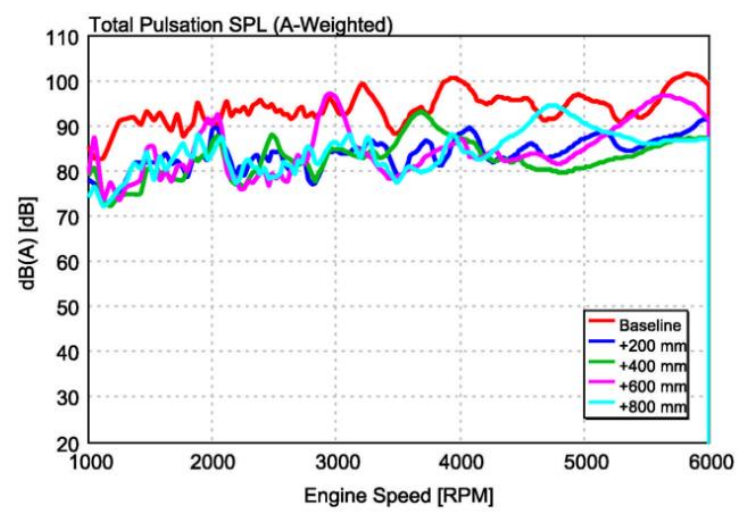

(a)

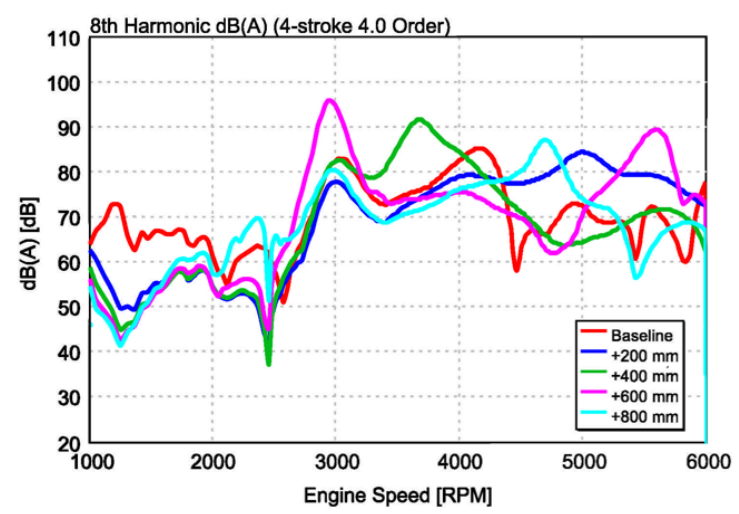

(c)

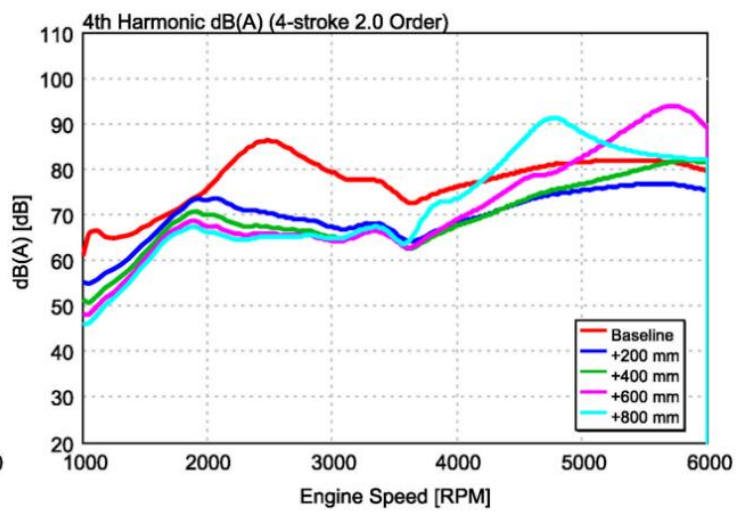

(b)

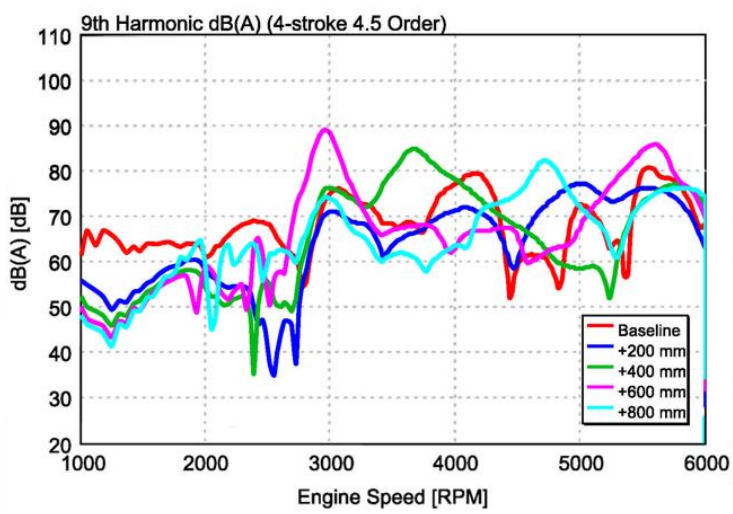

(d) 


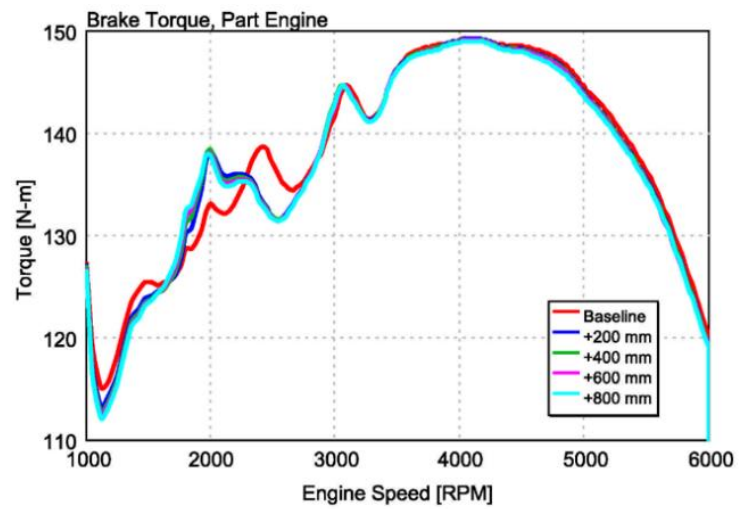

(e)

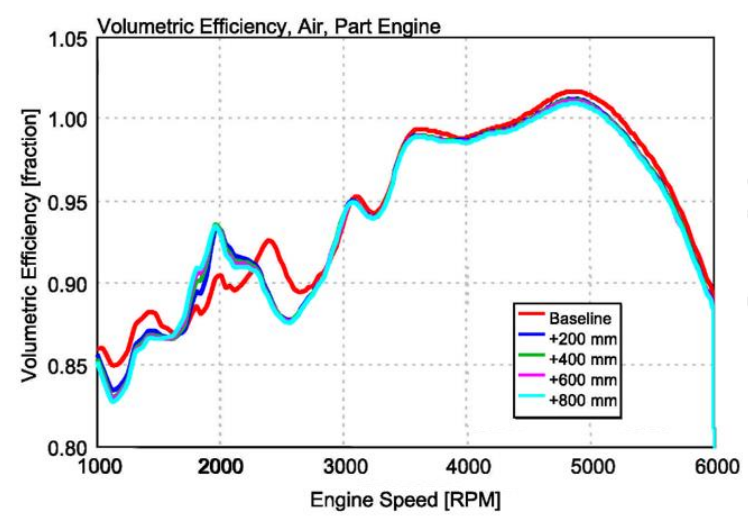

$(\mathrm{g})$

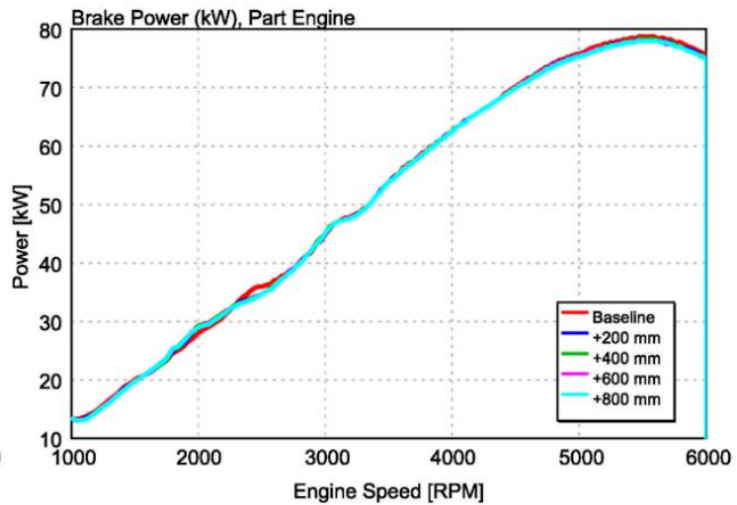

(f)

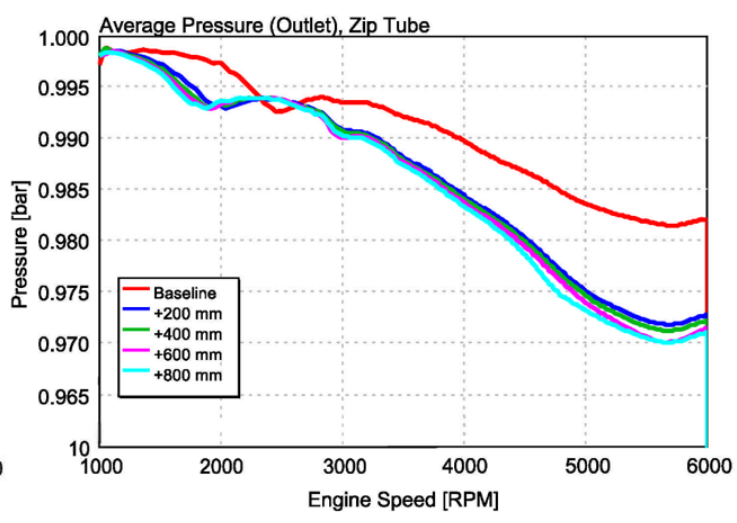

(h)

Figure 16. Simulation of SPL at (a) total pulsation; (b) fourth harmonic, 4-stroke, second order; (c). eight harmonic, 4-stroke, fourth order; (d) ninth harmonic, 4-stroke, $4.5^{\text {th }}$ order; and engine (e) brake torque; (f) brake power; (g) volumetric efficiency and;

(h) Air intake outlet average pressure at various duct length.

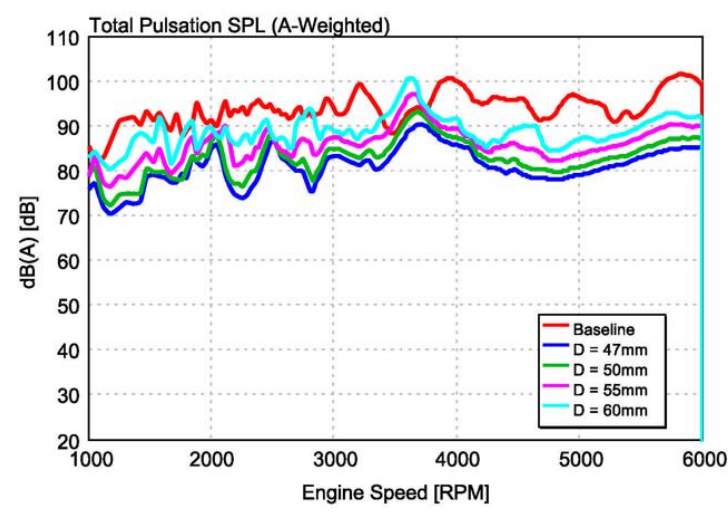

(a)

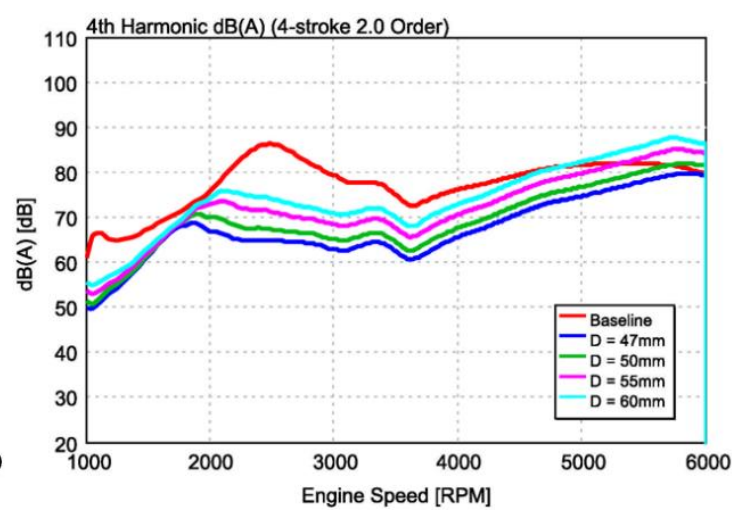

(b) 


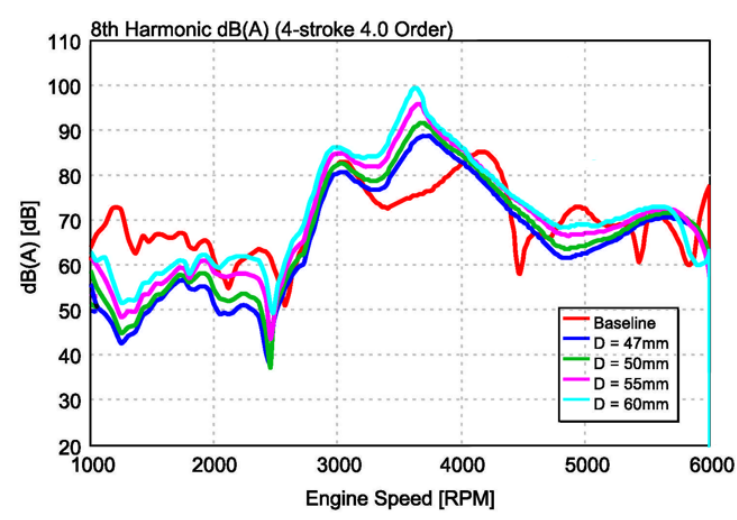

(c)

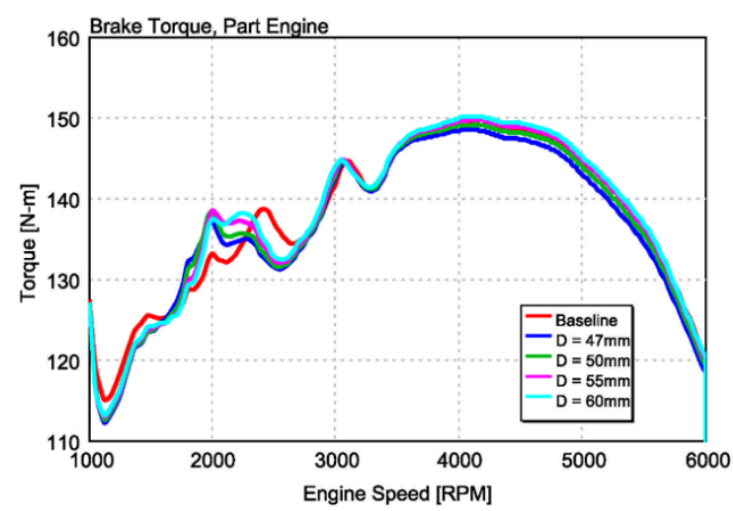

(e)

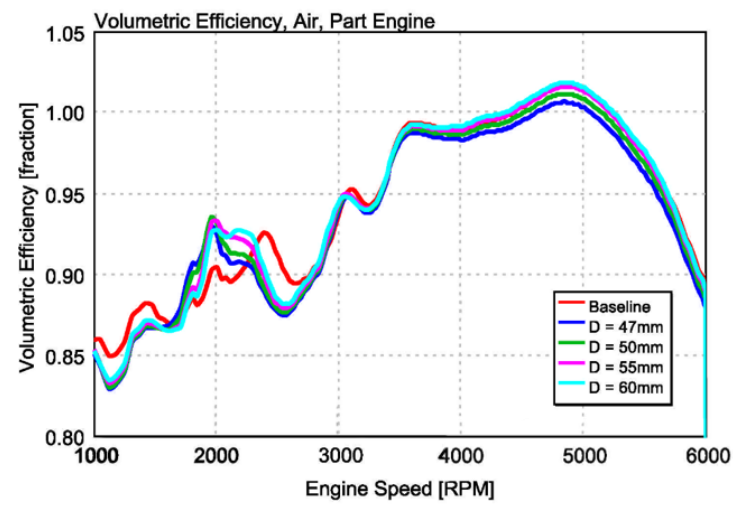

(g)

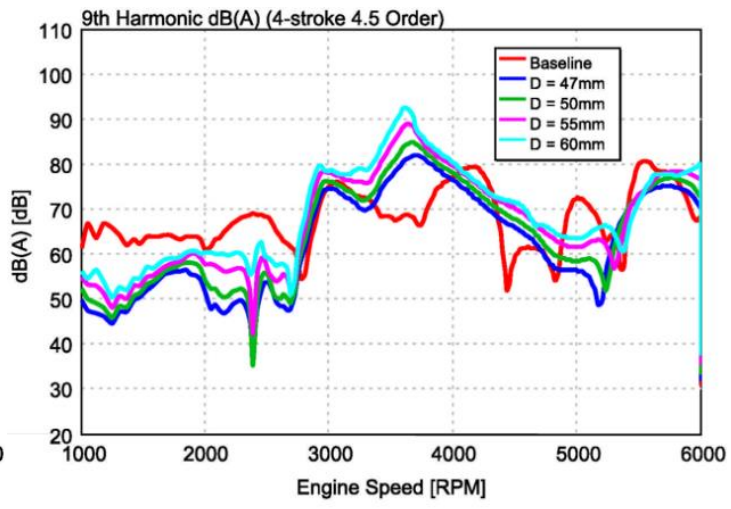

(d)

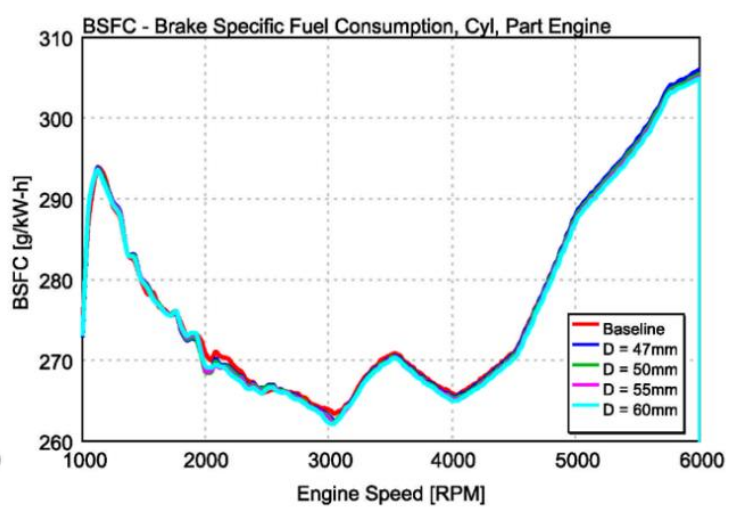

(f)

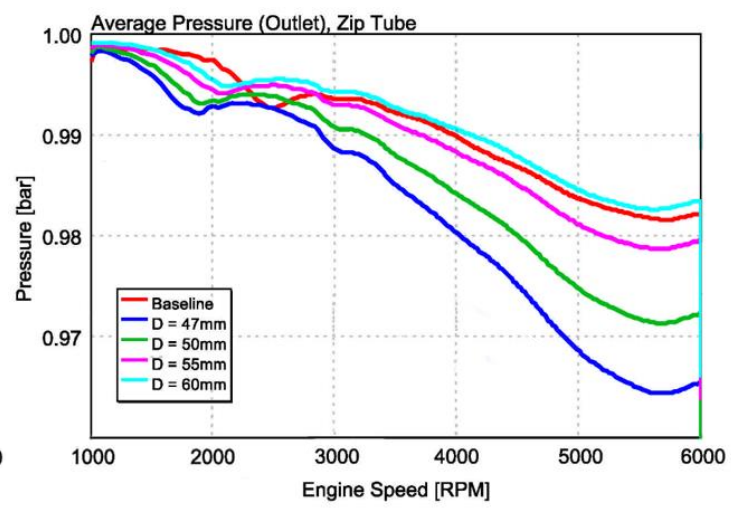

(h)

Figure 17. Simulated SPL at (a) total pulsation; (b) fourth harmonic, 4-stroke, second order; (c) eight harmonic, 4-stroke, fourth order and; (d) ninth harmonic, 4-stroke, $4.5^{\text {th }}$ order and; engine (e) brake torque; (f) brake power; (g) volumetric efficiency and; (h) air intake outlet average pressure at various duct diameter.

\section{PROPOSED AIR INTAKE MODULE DESIGN}

Base on the analysis and finding from Propose $2 \mathrm{~A}$, the proposed improved version of Propose 2A for prototype fabrication and evaluation testing. Figure 18 shows the configuration of the proposed design. Therefore, the final propose for the design is diameter of intake duct before the airbox is set to $50 \mathrm{~mm}$, while additional of $400 \mathrm{~mm}$ of 
duct length is recommended. This configuration was simulated and compared to the baseline model as shown in Figure 19.

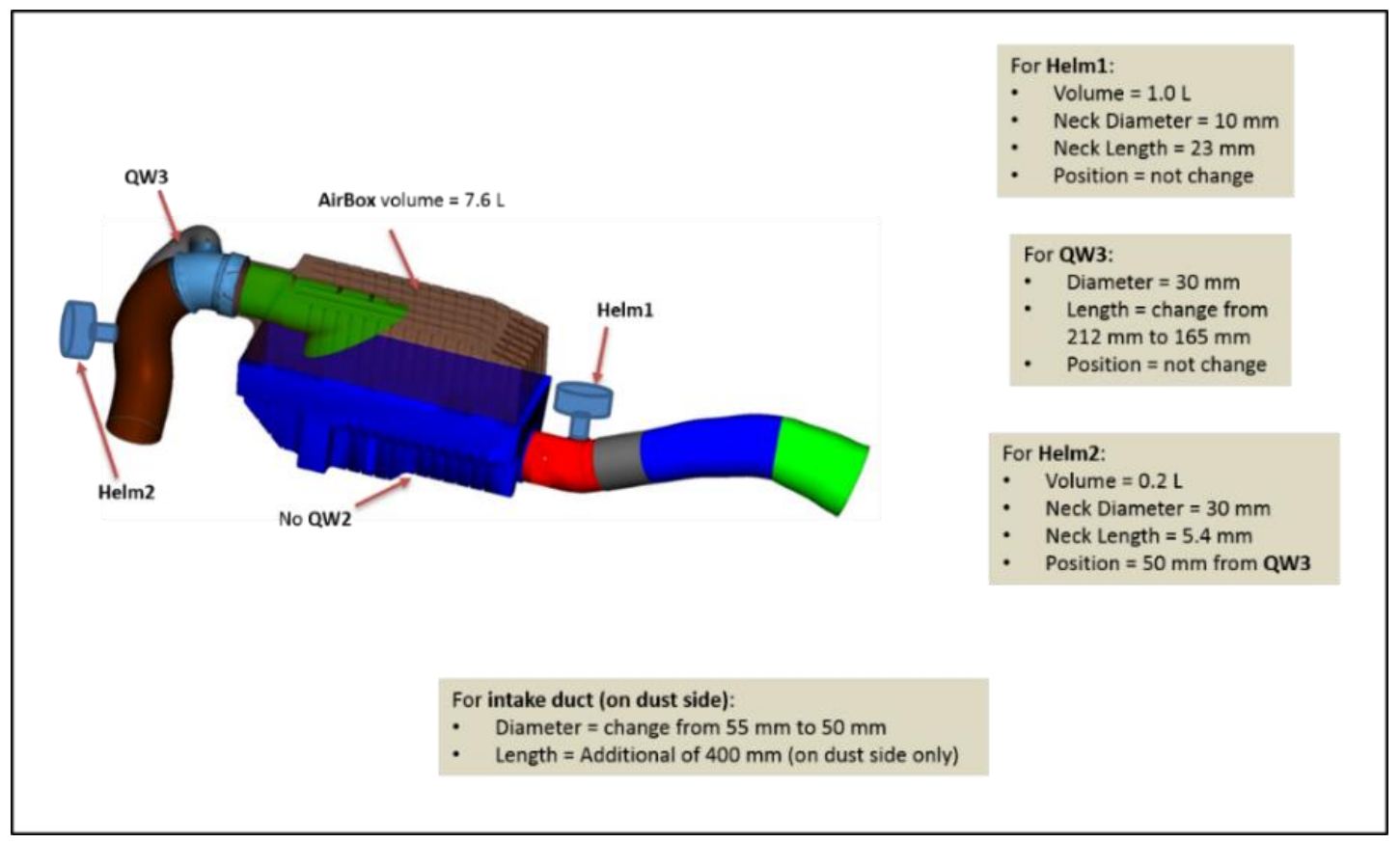

Figure 18. Propose improved design of air intake module.

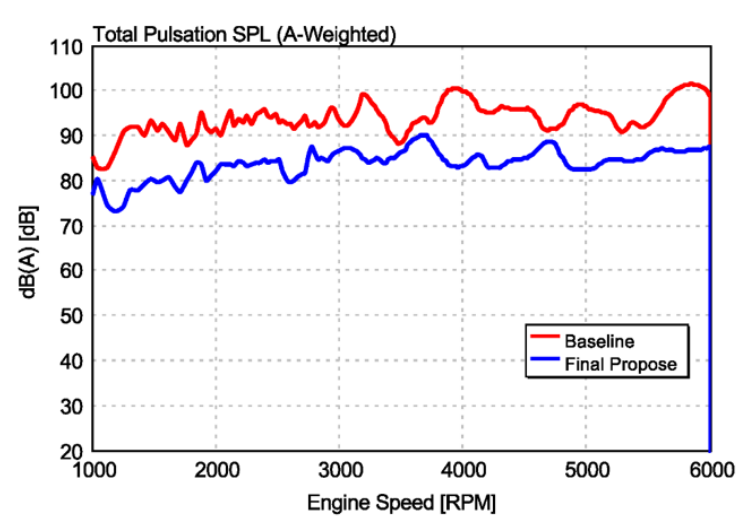

(a)

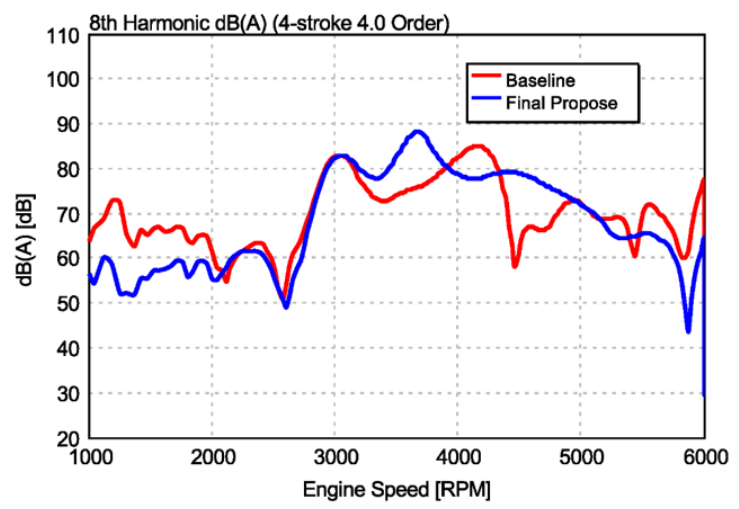

(c)

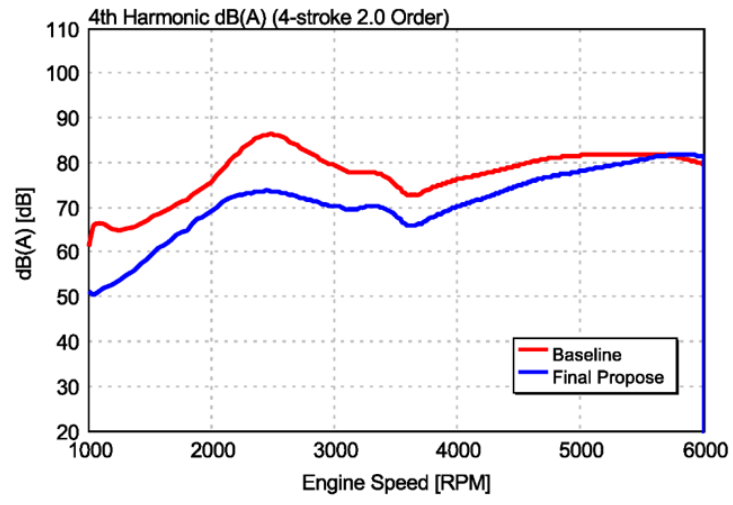

(b)

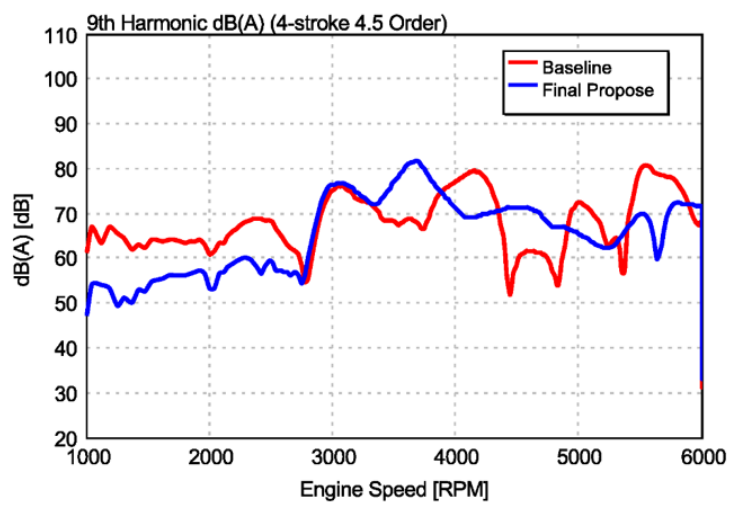

(d) 


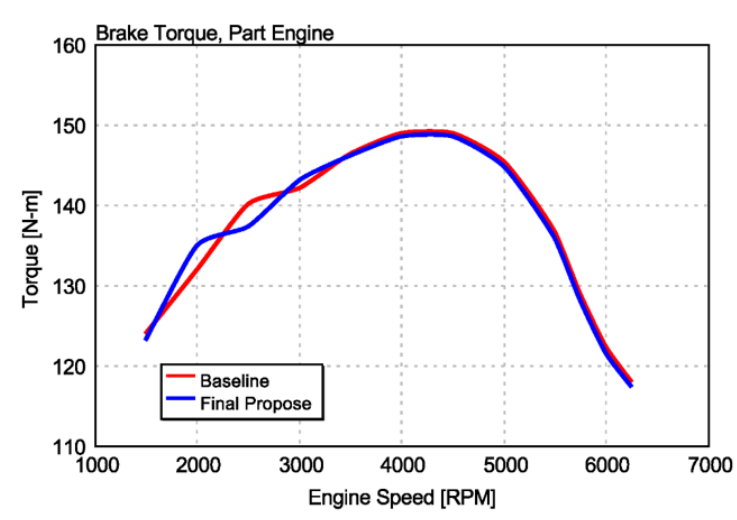

(e)

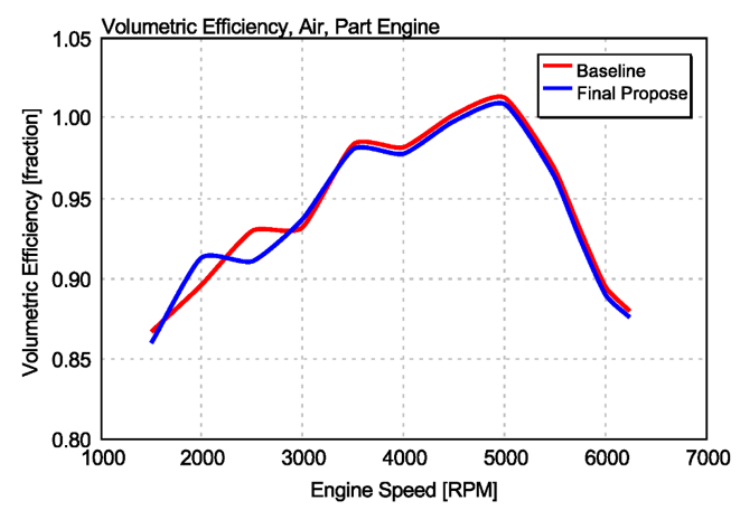

$(\mathrm{g})$

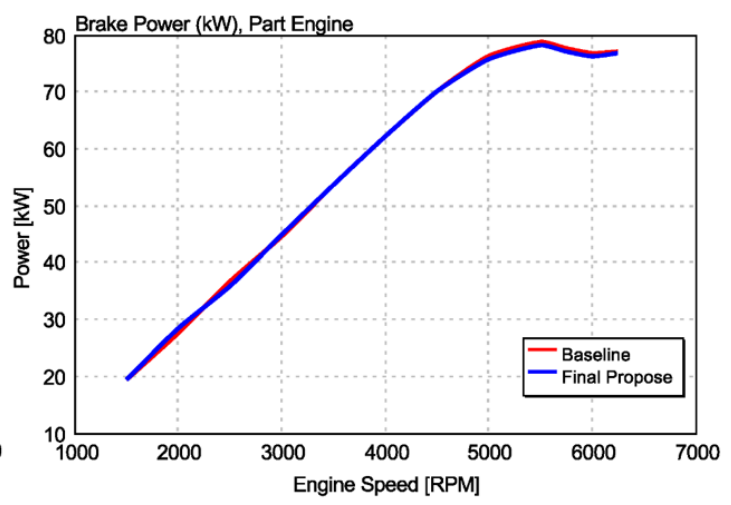

(f)

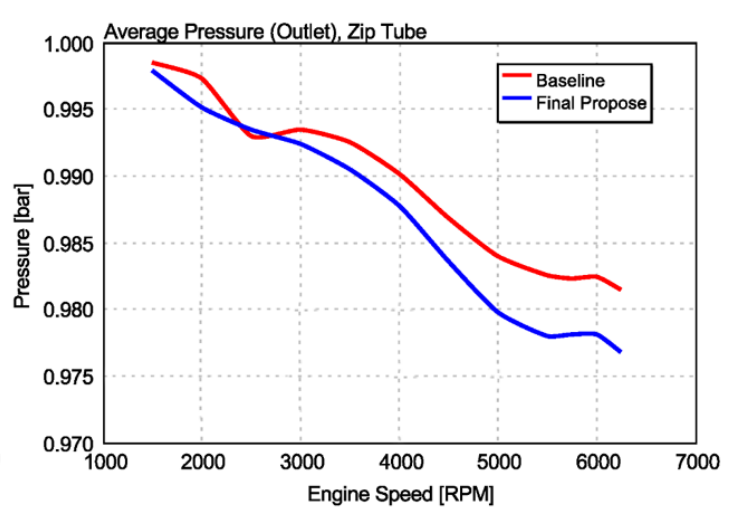

(h)

Figure 19. Comparison of proposed design with baseline from simulated SPL at (a) total pulsation; (b) fourth harmonic, 4-stroke, second order; (c) eight harmonic, 4-stroke, fourth order and; (d) ninth harmonic, 4-stroke, $4.5^{\text {th }}$ order; and engine (e) brake torque;

(f) brake power; (g) volumetric efficiency and; (h) air intake outlet average pressure.

\section{CONCLUSION}

This paper focused on the development of 1D engine model for acoustic study to improve acoustic of air intake module system. The conclusions of this study are:

i. The acoustic performance of the system is well analyzed and predicted according to the simulation results of the air intake module.

ii. 1-dimensional analysis method reduces product development time and cost involved in tuning the air intake module design.

iii. The placement and geometry of the resonator give effects to the sound dampening performance of the air intake system.

iv. The recommended modifications on the original air intake parameters involves the intake duct where diameter of intake duct before the airbox is set to $50 \mathrm{~mm}$, with additional duct length of $400 \mathrm{~mm}$.

v. The recommended modifications give impact to the volumetric efficiency and torque of the engine which increase at $2000 \mathrm{rpm}$ and decrease at $2500 \mathrm{rpm}$ engine speed. 


\section{ACKNOWLEDGEMENT}

The authors acknowledge the financial support from Ministry of Higher Education Malaysia (MOHE) under the FRGS grant R.J130000.7824.4F884. Appreciation also goes to powertrain department, PROTON Shah Alam for assisting in this study.

\section{REFERENCES}

[1] Patel M. A Review on Noise Sources and Methods of Reduction of Noise in Diesel Engines. International Journal of Engineering Sciences \& Research Technology. 2015;1:601-7.

[2] Panda KC. Dealing with Noise and Vibration in Automotive Industry. Procedia Engineering. 2016;144:1167-74.

[3] Guo R, Tang W-b, Zhu W-w. Acoustic performance and flow analysis of a multichamber perforated resonator for the intake system of a turbocharged engine. Proceedings of the Institution of Mechanical Engineers, Part D: Journal of Automobile Engineering. 2016:0954407016633563.

[4] Meduri SSS, Sundaram V, Kumar S S. A Novel Approach to Optimize the Resonators for Air Induction System. SAE 2016 World Congress and Exhibition: SAE International; 2016. p. 2016-01-1320.

[5] Britto VAJ, Karmakar S, Muthuveeraswamy M, Natarajasundaram B. High Speed Booming Noise Reduction in Passenger Car by Application of Cost Optimized NVH Solution. International Mobility Conference: SAE International 2016. p. 2016-28-0039.

[6] Mao Q, Pietrzko S. Semi-active Control Using Adaptive Helmholtz Resonators. Control of Noise and Structural Vibration: Springer; 2013. p. 267-323.

[7] Siano D, Aieollo R, D’Agostino D. Transmission loss assessment and optimization of an intake system for automotive application. International Journal of Mathematics and Computers in Simulation. 2016;10:82-9.

[8] Siano D, Teodosio L, De Bellis V, Bozza F. Analysis and Design of an Intake Filter Box for a Downsized VVA Engine. SAE 2014 World Congress \& Exhibition 2014. p. 2014-01-1693.

[9] Vaidya P, Hujare H. Optimization of Sound Pressure Level of Air Intake System by using GT-Power. International Journal of Emerging Science and Engineering. 2014;2:9-11.

[10] Guo R, Tang W-b, Zhu W-w. Comparison of 1D transfer matrix method and finite element method with tests for acoustic performance of multi-chamber perforated resonator. Applied Acoustics. 2016;112:140-6.

[11] Park C, Jeong J, Kim G, Kim D, Lee S-i, Lee H. A Study on the Acoustic Simulation for the Components of an Intake System. SAE 2011 Noise and Vibration Conference and Exhibition: SAE International; 2011. p. 2011-01-1520.

[12] Abdullah NR, Shahruddin NS, Mamat R, Ihsan Mamat A, Zulkifli A. Effects of air intake pressure on the engine performance, fuel economy and exhaust emissions of a small gasoline engine. Journal of Mechanical Engineering and Sciences. 2014;6:949-58.

[13] Allam S. Low Noise Intake System Development for Turbocharged IC Engines Using Compact High Frequency Side Branch Resonators. Advances in Powertrains and Automotives. 2015;1:12-23. 
[14] Montenegro G, Onorati A, Della Torre A. The prediction of silencer acoustical performances by 1D, 1D-3D and quasi-3D non-linear approaches. Computers \& Fluids. 2013;71:208-23. 